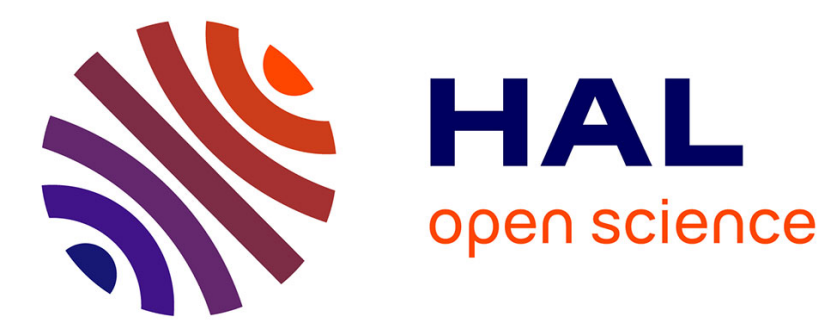

\title{
Recent growth trends of conifers across Western Europe are controlled by thermal and water constraints and favored by forest heterogeneity
}

Clémentine Ols, Jean-Christophe Hervé, Jean-Daniel Bontemps

\section{- To cite this version:}

Clémentine Ols, Jean-Christophe Hervé, Jean-Daniel Bontemps. Recent growth trends of conifers across Western Europe are controlled by thermal and water constraints and favored by forest heterogeneity. Science of the Total Environment, 2020, 742, pp.140453. 10.1016/j.scitotenv.2020.140453 . hal-02892840v2

\author{
HAL Id: hal-02892840 \\ https://hal.science/hal-02892840v2
}

Submitted on 19 Oct 2020

HAL is a multi-disciplinary open access archive for the deposit and dissemination of scientific research documents, whether they are published or not. The documents may come from teaching and research institutions in France or abroad, or from public or private research centers.
L'archive ouverte pluridisciplinaire HAL, est destinée au dépôt et à la diffusion de documents scientifiques de niveau recherche, publiés ou non, émanant des établissements d'enseignement et de recherche français ou étrangers, des laboratoires publics ou privés. 
Recent growth trends of conifers across Western Europe are controlled by thermal and water constraints and favored by forest heterogeneity

Clémentine $\mathrm{Ols}^{1 *}$, Jean-Christophe Hervé ${ }^{\dagger 1}$, Jean-Daniel Bontemps ${ }^{1}$

\author{
Affiliations : \\ ${ }^{1}$ Institut National de l'Information Géographique et Forestière, Laboratoire d'Inventaire \\ Forestier, 14 rue Girardet, 54000 Nancy, France. \\ ${ }^{\dagger}$ Contributed to the genesis of this pilot study, deceased on April $16^{\text {th }} 2017$ \\ ${ }^{*}$ Corresponding author \\ E-mail: clementine.ols@,ign.fr
}

Paper published in Science of the Total Environment, Volume 742, 10 November 2020 DOI: https://doi.org/10.1016/j.scitotenv.2020.140453 


\section{Highlights}

- Growth responses of pure and even-aged conifer forests were studied over 2006-2016

- Analyses were conducted using the French national forest inventory database

- Annual radial increment series were filtered-out from non-climatic signals

- Greater growth declines were associated with greater warming and drying

- Introduced forests were more prone to growth declines than native forests

\section{Graphical abstract}

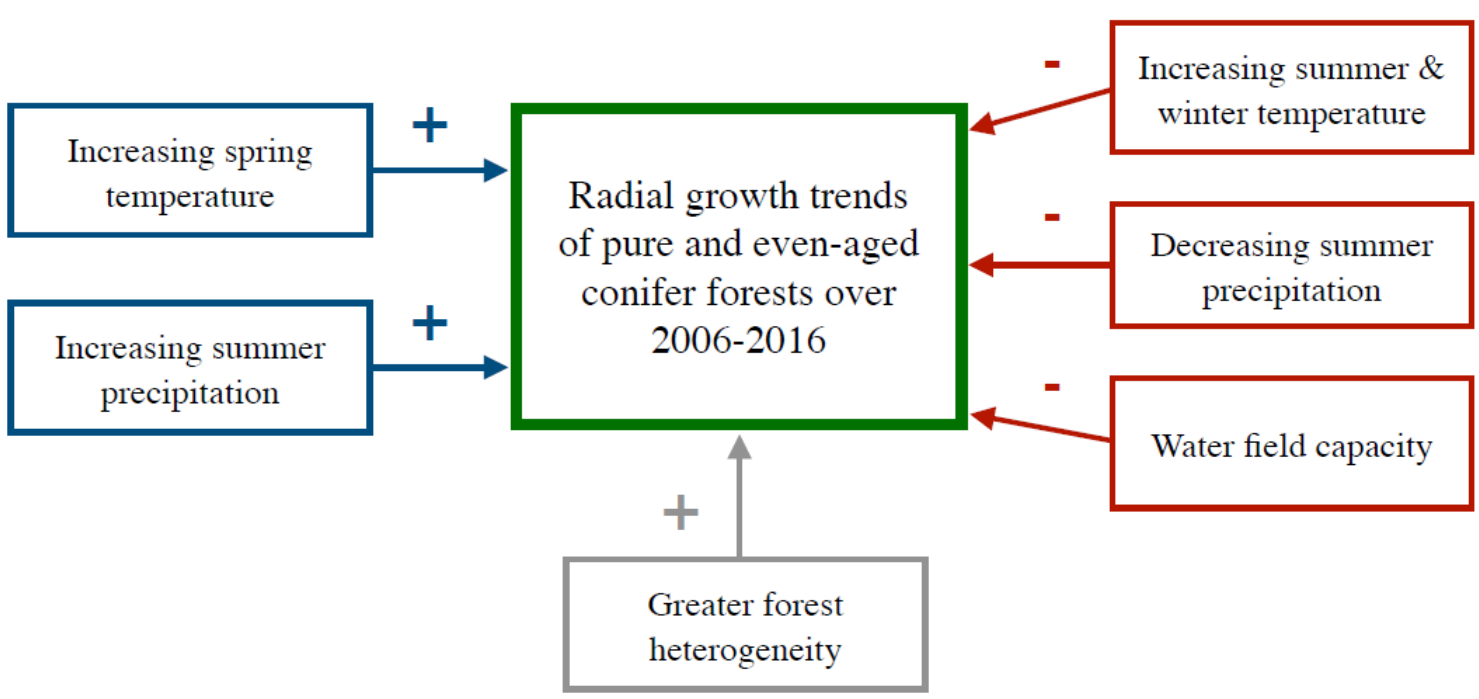

\section{Keywords}

Tree growth, Conifers, National forest inventory, Growth modeling, Climate change, Forest monitoring 


\section{Abstract}

Tree growing conditions are changing rapidly in the face of climate change. Capturing treegrowth response to such changes across environmental contexts and tree species calls for a continuous forest monitoring over space. Based on $>10,000$ tree-ring measurements sampled across the systematic grid of the continuous French national forest inventory (NFI) over the 2006-2016 period, we evaluated the radial growth trends of eight conifer tree species prevalent in European forests across their native and introduced ranges and various bioclimatic contexts ( $\mathrm{n}=16$ forest systems). For each forest system, radial increments were filtered out from tree, plot, soil and climatic normal influences to isolate environment-driven growth signals and quantify residual time-series. Associated growth trends across forest systems were then confronted against environmental variables (e.g. short-term averages and trends in seasonal climate). Trends for a given species were systematically more positive in cooler contexts (higher elevations or northern distribution margins) than in warmer contexts (plains). Decreases and increases in precipitation regimes were found to be associated with negative and positive tree growth trends, respectively. Remarkably, positive growth trends were mainly observed for native forest systems (7/9) and negative trends for introduced systems (5/7). Native forests showed a more heterogeneous forest structure as compared to introduced forests that, in line with observed positive dependence of tree growth trends onto both water availability and forest heterogeneity, appears to modulate the competitive pressure on water resource with ongoing summer maximum temperature increase. Over a short annually-resolved study period, we were able to capture tree growth responses coherent with climate change across diverse forest ecosystems. With ongoing accumulation of data, the continuous French NFI hence arises as powerful support to monitoring climate change effects on forests. 


\section{Introduction}

Trees continuously acclimate to their local environment for survival. Among tree growth constraints (e.g. tree-to-tree competition for nutrient resources and climate), the dynamic nature of climatic conditions is the most challenging for acclimation. Rapid ongoing climate change has put forests in the face of unprecedented growing conditions characterized by increased temperatures, altered precipitation regimes and more frequent extreme climatic hazards (IPCC, 2014). Evaluating the response of forest ecosystems to new environmental trends remains challenging, due to climate variability across regions, context-specific attributes (e.g. soil types and tree density) modulating climate-growth interactions (Ibáñez et al., 2014; Navarro-Cerrillo et al., 2014) and the genetic differentiation among tree populations of a same tree species (Housset et al., 2018). These different challenges call for the implementation of a spatially-systematic and continuous monitoring of forest ecosystems. Over the past decades, scientists have been increasingly making use of public global treegrowth databases (e.g. ITRDB, Grissino-Mayer \& Fritts, 1997) to unravel climate-growth interactions at large spatial scales (Babst et al., 2019; Björklund et al., 2017; Seftigen et al., 2018). However, such databases have important limitations (Babst et al., 2018; Zhao et al., 2019), as they gather tree growth datasets collected with diverse, sometimes incompatible, methodologies biased towards the sampling of tree species and regions (forest ecosystems) where sensitivity to climate is exacerbated. Projections of forests responses to climate change based on such 'patchwork' databases have hence proven to be spatially inconsistent and to overestimate climate change impacts on forest growth across large territories (Klesse et al., 2018). Last, site-specific information is mostly not accessible from such databases (e.g. not uploaded by the collector or simply not collected in the field) limiting the possibilities to properly isolate the effects of climate on forest growth. 
Ongoing environmental changes call for a real-time monitoring of forests to continuously update information on ecosystems' trends. Unlike global databases, national forest inventories (NFI) rely on a statistical design able to systematically monitor forest growth patterns over large geographical extents without any sampling bias (Klesse et al., 2018). NFI also provide, through regular annual or multi-annual field campaigns, valuable and constantly updated time-series of forest characteristics. The combination of spatial comprehensiveness and regular or continuous implementation thus provides an invaluable support for a spatiotemporal monitoring of forest systems for a large panel of features (e.g. growth and health; Aguirre, del Río, \& Condés, 2019; Charru, Seynave, Hervé, Bertrand, \& Bontemps, 2017; Girardin et al., 2016; Ols et al., 2018).

France is one of the few countries worldwide, together with Sweden and the U.S.A., to implement a continuous NFI whereby the entire country is inventoried every year based on a national grid (Hervé, 2016; Tomppo et al., 2010). France also presents one of the largest European climatic diversity with oceanic, continental, Mediterranean and mountain climates. Its marked topography (five mountain ranges including the Alps) and soil type diversity have shaped the largest diversity of European forest types (Barbati et al., 2007) with about 70 different tree species and over a hundred of subsequent forest compositions (Bontemps et al., 2019; Morneau et al., 2008). It follows that most of European tree species are present on the French territory. These remarkable features make the French context a golden opportunity to initiate a systematic monitoring of tree growth responses to climate change (Charru et al., 2017,2013 ) that could provide relevant information for other forest regions across Europe. Forests cover $31 \%$ of the French territory, with conifer forests accounting for $21 \%$ of this forest area (IGN, 2018). Conifer species in France are mainly fast-growing species with clear and easy-to-measure tree rings and are encountered in all climatic types. Several French emblematic species are native from cold mountain and boreal contexts of Europe (e.g. 
Norway spruce and Scots pine) and Western North America (e.g. Douglas-fir), and these may not prove adapted to future climate regimes (Lévesque et al., 2013) or on the contrary may constitute silvicultural opportunities (Waring et al., 2008). Recently, unambiguous growth enhancement has been reported in colder contexts, i.e. at higher elevations or latitudes where coniferous species prevail (Charru et al., 2013; Kauppi et al., 2014; Wu et al., 2012). Conversely, in warmer contexts, such as plains and Mediterranean regions, conifer species (e.g. Aleppo pine and Scots pine) have displayed recent growth decline or stationary growth patterns (Charru et al., 2017). The possible climatic causes of these divergent trends have been insufficiently explored giving rise to a wide set of projected responses, notably for species such as Norway spruce, Scots pine, or silver fir (Mérian and Bontemps, 2014). Further, past significant efforts in afforesting agricultural lands with coniferous tree species (Andersson, 2005) offer the possibility to explore species acclimation to climate change according to their growing context (native vs. introduced). Conifer species therefore constitute a perfect case-study for a comprehensive monitoring of climate change impacts on tree growth across environmental contexts.

In the present study, we investigated the recent growth patterns of eight conifer tree species prevalent in European forests across various bioclimatic regions and natural vs. afforested contexts in Metropolitan France. This study is the first to make use of more than 10,000 annual radial increments collected by the French NFI over the 2006-2016 period. Pure and even-aged stands were taken as reference communities for assessing environmental influence on growth (Dunson and Travis, 1991). Radial growth was modeled using numerous tree- and site-level factors $(\mathrm{n}>40)$ to remove all but time-changing environmental effects encoded in radial growth measurements. The remaining inter-annual growth variability was then compared to average climate and ongoing trends in climate. Four hypotheses regarding tree growth sensitivity to climate change were also tested: (H1) Radial growth is affected by 
temperature warming, with warming during the cold seasons and higher minimum temperatures favoring growth and warming during the warm seasons and higher maximum temperature disfavoring growth; (H2) Radial growth is limited by precipitation and this constraint can be exacerbated by climate warming; (H3) Radial growth is limited by tree-totree competition with respect to water (precipitation) and nutrient resources (soil fertility); (H4) forest systems based on introduced conifer tree species are more prone to growth decline in the face of climatic change than those based on native tree species. This study is a first step in building a continuous monitoring system of tree growth designed to be updated annually with new NFI data.

\section{Material and methods}

\section{$2.1 \quad$ The French national forest inventory}

Since 2005, the French NFI has adopted an annualized systematic sampling design based on a $1 \mathrm{~km} \times 1 \mathrm{~km}$ grid (Hervé, 2016). Every year, one tenth of the grid is inventoried (Fig. 1A) and about 6,000 plots classified as forests by the photo interpretation of aerial images are visited in the field in order to deliver fully renewed information on forests. Sampling plots are temporary and consist in 25-m radius circles within which forest composition and structure, ground vegetation, soil conditions and topography (slope, exposition, soil type, etc.) are described. Tree measurements are also extensively taken (e.g. species, stem damage, circumference, height, morphology and growth). In addition, since 2007 tree cores are sampled on two dominants trees (chosen within the main tree species encountered on the plot) for annual radial increment (RI) measurements. Cores are extracted at breast height (approx. $1.30 \mathrm{~m}$ above ground) perpendicularly to the stem using an increment borer, mounted and measured for annual RI directly in the field with a precision of $1 / 10 \mathrm{~mm}$ using a magnifier. Annual RI measurements include the width of the last completed tree ring formed by the 
sampled trees (e.g.in 2007, the ring of 2006 is measured, and the often incomplete ring of the running year is excluded). More information about the French forest inventory can be found in Vidal, Alberdi, Hernandez, \& Redmond, 2016 and on http://inventaire.forestier.ign.fr (English version available). Eleven field campaigns have been completed between 2007 and 2017.

\subsection{Study area and tree species}

The present study covers the entire French territory (Fig. 2A) partitioned into 11 ecological regions representative of the diverse bioclimatic growing environments of western Europe (plain and mountainous contexts and, oceanic, continental and Mediterranean climates; Figs. 2A-B \& A1-A2 in Appendix A). The delimitation between ecological regions was based upon climatic characteristics, geology, hydrology, and vegetation type (Cavaignac, 2009). We studied the radial growth of eight conifer tree species prevalent in European forests across these ecological regions, in their native and /or introduced contexts. These included Douglasfir (DF, Pseudotsuga menziesii Mirb. Franco), Norway spruce (NS, Picea abies Karst.), silver fir (SF, Abies alba Mill.), European larch (EL, Larix decidua Mill.), scots pine (SP, Pinus sylvestris L.), maritime pine (MP, Pinus pinaster Ait.), Corsican pine (CP, Pinus nigra subsp. laricio Maire) and, Aleppo pine (AP, Pinus halepensis Mill.). Douglas-fir originates from North America and has been heavily introduced in France during the second half of the $20^{\text {th }}$ century. While native from the Alps and the Vosges mountains, Norway spruce has been largely introduced in other contexts throughout the metropolitan territory since the $19^{\text {th }}$ century including the Massif Central mountain range and plains. Silver fir is native of most mid-elevation mountainous ranges in Europe. European larch is mainly encountered in the Alps where it is considered native but where it has been massively planted during the $19^{\text {th }}$ century using Italian provenances to stabilize and restore sloping grounds. Scots pine is native 
of the Alps and the Massif Central, and has been introduced in northern plain contexts since the $19^{\text {th }}$ century. Maritime pine is native of northern Africa and southern Europe and has been implanted in the South West of France in the mid $-19^{\text {th }}$ century and more recently in northern plain contexts. Corsican pine originates from Corsica and more largely Mediterranean contexts but has been introduced in the northern plains in the $20^{\text {th }}$ century. Aleppo pine is only found within its native Mediterranean range. Natural distribution maps elaborated by the European Forest Genetic Resources program (http://www.euforgen.org/species/) can be found in Appendix B.

\section{$2.3 \quad$ Selection of forest systems}

A forest system was defined by a single tree species growing in pure and regular forest stands within a specific ecological region growing. Growth dynamics in such systems can be easily and modeled (forest production theory, Skovsgaard \& Vanclay, 2007). These systems have therefore been advocated as the most accurate in the evaluation of ecosystem responses to their abiotic environment (Dunson and Travis, 1991). Further, these systems correspond to those of introduced coniferous tree species, object of the present study. Data pre-selection was performed on pure and even-aged NFI plots sampled between 2007 and 2017. Pure plots were defined as stands where the basal area of one of the eight target tree species accounted for at least $80 \%$ of the total basal area. Even-aged plots were defined as stands classified in the field as regular high forest (i.e. with a regular high vertical structure). Then, all pre-selected plots that had been wind-damaged by storms, such as those affected by the 2009 Klaus storm in the southwest of France (maritime pine region), were removed from further analysis to minimize interference with tree-ring variability. To ensure a representative radial growth modeling, we further restricted our selection to forest systems covered by at least 20 increment cores (26 RI measurements/13 plots per year on average over the study period). The period covered by RI data is 2006-2016 (current ring not measured in the field, see section 2.1). For four tree 
species (Douglas-fir, Scots pine, Corsican pin and Aleppo pine), the number of RI data selected in three plain ecological regions (crystalline and oceanic west [W], semi-oceanic central north [N] and semi-continental east [E], see Fig. A2) was insufficient. In these cases, we aggregated multi-regional data into one single region named 'northern plains' (Table 1). Species-specific maps of the location of selected RI data across ecological regions are presented in Fig. A2. In total, 16 forest systems could be studied (Table 1 and Fig. 2B-D). Their respective annual sample depth is presented in Table A1. Each forest system was finally classified as either native or introduced based on species-specific natural distribution maps elaborated by the European Forest Genetic Resources program (http://www.euforgen.org/species/, Appendix B; but see also section 2.2).

\subsection{Stand and site data}

The French NFI collects a comprehensive set of auxiliary data characterizing the environmental conditions in which trees are growing, useful to circumvent the effects of local environment on RI variability. To describe the competition environment of sampled trees, we computed the stand basal area $(\mathrm{G})$ at a $1.30 \mathrm{~m}$ height, the proportion of the target species in basal area $\left(\mathrm{G}_{\mathrm{sp}}\right)$, the plot quadratic mean diameter $(\mathrm{QMD})$, Reineke's relative density index (RDI; Reineke, 1933) and, the Gini index, as a measure of stem size heterogeneity in the plot (ranging between 0 and 1, with perfectly homogeneous and singularly heterogeneous stands having a Gini index of 0 and 1, respectively). We also computed the basal area of trees larger than the targeted trees (BAL; Schütz, 1975) and a measure of the social rank (diameter/QMD) of targeted trees. Soil variables were further selected to describe the nutritional status of the plot, and included soil depth, soil type, maximum field water capacity at a $1 \mathrm{~m}$-depth and indices of soil texture, acidity, rockiness and, water content. In addition, indicators of soil $\mathrm{pH}$, carbon-to-nitrogen $(\mathrm{C}: \mathrm{N})$ ratio, phosphorous and, temporary and permanent logging were 
used (Gégout, 2006; Kuhn, 2016). These indicators are computed annually for all NFI plots based on quantitative bio-indication by the ground vegetation described in the field and an Ellenberg's philosophy (Ellenberg, 2009), whereby each species characterizes a specific range of soil conditions. The complete list of tree-, stand- and site-specific variables used in the modeling of RI and, their average values across plots of a specific forest system are presented in Tables A2 and A3, respectively. Differences across native and introduced systems are presented in Figure A3. Major discrepancies $(P<0.1)$ included a significantly more heterogeneous structure (greater Gini index), a lower water field capacity and sampled dominant trees that were bigger, older and socially more dominant in native systems than in introduced systems (Fig. A3).

\section{$2.5 \quad$ Climate data}

Plot-specific seasonal climate data over the 1976-2016 period were extracted from the European $0.25^{\circ} \times 0.25^{\circ}$ E-OBS dataset (Cornes, van der Schrier, van den Besselaar, \& Jones, 2018, https://www.ecad.eu). The climatic conditions of each NFI plot were assumed to correspond to those of the grid cell it was located in. Some NFI plots therefore presented identical climate attributes. Climate variables included minimum temperature (Tmin), mean temperature (Tmean), maximum temperature (Tmax) and precipitation sums (Prec). Seasonal climate variables (spring-MAM, summer-JJA, autumn-SON, winter-DJF) were computed as the robust bi-weighted mean (sum for precipitation) of monthly variables. To account for long-term average climate effects within radial growth data, we also computed plot-specific climatologic standard normals (thereafter climatic normals) for all seasonal precipitation and temperature variables over the $1976-2005$ period, i.e. the 30 -yr period before the first year of the 2006-2016 study period. Lastly, to compare the annual residuals of radial growth modeling to short-term climate characteristics, we computed plot-specific averages and trends 
in seasonal climate over the 2006-2016 period (Tables C1 \& C2 in Appendix C). Seasonal climatic normals, averages and trends at the forest system level were computed as the robust bi-weighted mean of plot-specific data (Tables 1 \& A3 and Fig. 2). Differences between native and introduced systems in both climate averages and trends in climate at the annual and seasonal level over the study period are presented in Figures $\mathbf{C 1 7} \& \mathbf{C 1 8}$ (but see also section 3.2). The coarse spatial resolution of the herein used climate datasets (approx. $28 \mathrm{~km}$ of horizontal resolution), while not adequate for site-specific analyses, arises as a good compromise for climate-growth analyses performed at the regional scale (e.g. focusing on regional forest systems) using seasonal and 30-yr average seasonal climatic variables.

\subsection{Radial growth modeling framework}

To investigate the impact of recent environmental change on tree growth, a modeling approach was developed to filter out all but effects of a time-changing environment on RI, i.e. the influence of recent climate change we intended to explore (see summary flowchart in Fig. 1). This approach combines annual RI from each successive systematic inventories of the forest system under study, extracted from spatially-distinct temporary plot samples (Fig. 1A), in order to aggregate the filtered signal into one single time series. A model was built for each forest system. RI was modeled as a function of dendrometric and bioclimatic variables (Fig. 1B), e.g. soil nutritional and water indicators and climatic normals (see Table A2 for the complete list of predictive variables tested). The calendar year was introduced as a factor (Fig. 1B; each year forming a level of this factor) and the year 2006, year corresponding to the first annual radial increment measurements, defined as the reference year from which to quantify annual growth anomalies. This methodology allows producing a unique time series of comparable growth anomalies for each forest system under study (Fig. 1C). To prevent total tree height from masking the effect of other soil fertility variables (Bontemps and 
Bouriaud, 2014), total height was not included in the models. Contrasts of all categorical variables, but calendar year, were parameterized using the contr.sum ("sum to zero contrasts") function in $\mathrm{R}$ to constrain the coefficients of all contrasts to add up to 0 . Last, since heteroscedasticity affected the model residuals (inconstant variance) as usually observed in tree growth data, we introduced a Box-Cox transformation of the predicted variable (with empirical correction for bias of prediction as described in Fischer et al. 2016). Model construction was performed as follows:

$B C(R I)=\sum_{k=1}^{n} a_{k} f_{k}\left(\operatorname{var}_{k}\right)+Y e a r+\varepsilon$

Where $\mathrm{BC}$ is the Box-Cox transformation (Box and Cox, 1964) of the input variable RI, $f_{\mathrm{k}}$ are non-parametric transformation of the quantitative predictors $(\mathrm{x}, \ln (\mathrm{x}), \mathrm{x}+\ln (\mathrm{x}), 1 / \mathrm{x}, \mathrm{x}+1 / \mathrm{x}$ or, $\left.\mathrm{x}^{2}+\mathrm{x}\right)$ capturing the effects of predictive variables $\operatorname{var}_{k}$ [all categorical predictors were added to the model untransformed], $a_{k}$ the estimated parameter for $f_{k}\left(\right.$ var $\left._{k}\right)$, Year is a categorical variable representing the respective calendar year of RI measurements and, $\varepsilon$ is the error of the model assumed to be $\mathrm{N} \sim(0, \boldsymbol{\sigma})$, where $\boldsymbol{\sigma}$ is the residual standard error (RSE) of the model.

In a Box-Cox model, the relationship between the original $(y)$ and the transformed dependent variable $\left(\mathrm{BC}(\mathrm{y})=\mathrm{y}^{\prime}\right)$ is:
a. $y^{\prime}=\frac{y^{\lambda}-1}{\lambda}$ and
b. $y=\left(y^{\prime} \times \lambda+1\right)^{\frac{1}{\lambda}}$
with $\lambda \in \mathrm{R}$

where $\lambda$ is the Box-Cox power transformation parameter (when $\lambda=0$, the Box-Cox transformation is the natural log transformation).

The modeling steps were as follows. First, variables were added one by one to the model and tested for significance. Then, seasonal climatic normals were added all at once in the model and significant normals selected through stepwise backward and forward algorithm using the step function. Models selection was performed using successive likelihood ratio test (LRT) statistics for nested models (Solomon, 1975) and with the anova function. Last, the variable 
Year was added into the model and kept within the model regardless of its significance. This variable captures the effect of each calendar year on radial growth increment variability $\left(\widehat{\mathrm{Y}}_{1}\right)$ by expressing the annual growth deviation of a specific year as a fraction of the growth during a pre-defined reference year. This computation allows the extraction of annual growth anomalies (see section 2.7 and Appendix D). A significant year effect indicates that, all other growth-influencing factors taken into account, radial growth variability is significantly affected by an annual time-changing phenomenon. The Box-Cox power transformation parameter $\lambda$ was estimated by the log-likelihood criterion using the boxcox function in the MASS package (Venables \& Ripley, 2002, Table 2). All modeling procedures were performed in the R statistical programming environment (R Core Team, 2015).

\subsection{Construction of growth anomaly chronologies}

A relative growth anomaly chronology was built for each forest system, in which the annual growth deviation of a specific year was expressed as a fraction (percent deviation) of the average growth level during the reference year 2006 (Fig. 1C). The relative growth anomaly coefficient of a given year $i\left(\widehat{A_{l}}\right)$ compared to the reference year was computed as:

$\widehat{A_{l}}=\frac{B C^{-1}\left(\widehat{M}+\widehat{Y}_{l}\right) \times B}{B C^{-1}(\widehat{M}) \times B}=\frac{B C^{-1}\left(\widehat{M}+\widehat{Y}_{l}\right)}{B C^{-1}(\widehat{M})}$

Where $\widehat{\bar{M}}=\sum \widehat{a_{k}} f_{k}\left(\overline{v a r}_{k}\right), B$ is the average empirical bias of the Box-Cox transformation (see Fischer, 2016) and $\widehat{Y}_{l}$ is the estimated effect of year $i$.

To investigate the significance of trends in growth anomaly coefficients across forest systems, the upper and lower margins of the $95 \%$ bilateral confidence interval of a growth anomaly coefficient $\left(\widehat{A_{l}}\right)$ were computed as:

$$
\begin{aligned}
& \widehat{C I_{\text {sup }}}=\frac{B C^{-1}\left(\widehat{M}+\widehat{Y}_{l}+1.96 \times \widehat{S E}_{l}\right)}{B C^{-1}(\hat{M})} \\
& \widehat{C I_{\text {lnf }}}=\frac{B C^{-1}\left(\widehat{\bar{M}}+\widehat{Y}_{l}-1.96 \times \widehat{S E}_{l}\right)}{B C^{-1}(\widehat{M})}
\end{aligned}
$$


Where $\widehat{S E}_{l}$ is the standard error associated with $\widehat{Y}_{l}$.

The control or 'reference' year has by definition an anomaly of $1\left(\overline{A_{\text {ref }}}=1\right)$ and no standard deviation $\left(\widehat{S E_{r e f}}=0\right)$. For more details regarding the mathematical computation of relative chronologies, see Appendix D. Following the construction of chronologies, relative chronologies were converted into absolute growth anomaly chronologies (thereafter growth chronologies) by multiplying relative growth anomaly coefficients by the average growth level during the 2006 reference year. We finally estimated trends in growth chronologies (thereafter growth trends) over the 2006-2016 period as defined by the slopes of the linear regression of annual anomaly coefficients against time.

\subsection{Relationships between growth trends across forest systems and their average growing} environment

To identify biotic and abiotic factors driving growth trends, a systematic screening based on a series of univariate linear regressions was performed. Regional averages of biotic (e.g. tree-totree competition and forest structure) and abiotic (e.g. seasonal climate) predictors were computed across model-specific data sets (e.g. sampled trees and stand characteristics, soil parameters, and seasonal climatic normals; see Table 2 for a comprehensive list of environmental indicators). Significant relationships were then further combined into bivariate linear regressions to test three hypotheses regarding growth limiting constraints: (H1) Radial growth is affected by temperature warming, with warming during the cold seasons and higher minimum temperatures favoring growth and warming during the warm seasons and higher maximum temperature disfavoring growth; $(\mathbf{H 2})$ Radial growth is limited by precipitation and this constraint can be exacerbated by climate warming; (H3) Radial growth is limited by treeto-tree competition with respect to water (precipitation) and nutrient resources (soil fertility). 
Multivariate regression analyses (more than two variables) were finally performed to determine the growth-controlling hierarchy between temperature, precipitation, competition, and soil resources variables.

\subsection{Effect of tree species origin on current growth responses at a forest system level}

We further formulate and tested that (H4) forest systems based on introduced conifer tree species are more prone to growth decline in the face of climatic change than those based on native tree species. The effect of this 'Origin' variable was compared simultaneously in twovariable regression models with those of significant biotic and abiotic predictors identified in the previous approach. The significance and sign of the statistical effect of each variable was carefully analyzed to investigate growth dynamic and climate adaptation differences across native and introduced forest systems.

\section{Results}

\subsection{Regional models and growth chronologies}

Regional models captured between 14 \% (Norway spruce in Massif Central, NS-MC) and $41 \%$ (maritime pine in the oceanic south-west, MP-SW) of the total variation in RI measurements (Table 2). The effect of the calendar year variable was significant $(P<0.05)$ in 13 out of 16 models, underlining that the annual variability of RI anomalies across forest systems is controlled by time-changing phenomena (e.g. climate variability; Tables 2 \& A4.D in Appendix A). Radial growth trends over the study period varied between $-30 \%$ and +86 \% across forest systems (Table 2 and Figs. 3 \& E1 in Appendix E). Out of 16 growth chronologies, nine presented positive trends and seven negative trends over the 2006-2016 period. Remarkably, most positive trends were observed for native forest systems (7 out of 9) and most negative trends were observed for introduced forest systems ( 6 out of 7 , Table 2 
and Fig. 4A). Four growth chronologies further presented significant $(P<0.05$, i.e. $95 \%$ confidence boundaries not overlapping) linear trends, both positive and negative, over the study period (Table 2). Douglas-fir, regardless of the region where it was introduced, showed significant negative growth trends. Scots pine displayed trends clearly structured along an elevation gradient with a slightly negative trend in the northern plains (mean elevation $=152$ m) the unique region where it has been introduced, a positive trend in the Massif Central $(\mathrm{elev} .=938 \mathrm{~m})$ and a significant positive trend in the Alps (elev. $=1117 \mathrm{~m}$; Table 2 and Fig. 3). Norway spruce also presented trends structured along an altitudinal gradient with a significant negative trend in the semi-continental east $(\mathrm{elev} .=327 \mathrm{~m})$, a negative trend in the Vosges $(\mathrm{elev} .=631 \mathrm{~m})$ and the Massif Central $(\mathrm{elev} .=951 \mathrm{~m})$, and a slightly positive trend in the Alps (elev. = 1365 m, Table 2 and Fig. 3). Silver fir showed positive trends in both the Vosges and the Massif Central, with a slightly stronger trend in the latter region. Maritime pine displayed positive trends across both the northern plains and the oceanic south-west with a slightly more positive trend in the former region where it has been recently introduced. European larch displayed a significant positive trend in the Alps. Corsican pine showed a slightly negative trend in northern plains. Aleppo pine showed a significant positive trend in the Mediterranean (Table 2 and Fig. 3).

Growth trends varied across regions for a given tree species, but also across tree species within a given region (Table 2 and Fig. E1). In the northern plains, a region where only introduced species could be studied, all species but maritime pine showed negative trends, with Norway spruce and Douglas-fir showing the strongest negative trends. In the Vosges (mid-elevation mountains), silver fir (native) presented a positive trend whereas Norway spruce (introduced) presented a negative trend. In the Massif Central, Scots pine and silver fir (both native) displayed positive trends while Douglas-fir and Norway spruce (both introduced) displayed negative trends (Table 2 and Fig. E1). In the Alps, where only native 
species were studied, all species showed positive trends, significant for Scots pine and European larch and not significant for Norway spruce (Table 2 and Fig. E1). In summary, tree species growth trends appeared to be predominantly structured according to elevation (mostly positive in the Alps, intermediate in mid-elevation mountain ranges, and most often negative in plains) and to the origin of tree species (generally positive for native tree species and negative for introduced tree species).

\subsection{Seasonal climate trends across forest systems}

Spring temperatures decreased regardless of the variable (Tmin, Tmean or Tmax), except for spring Tmax that increased in the three Alpine systems (Scots pine, Norway spruce and European larch) and in the 'Silver fir-Vosges' system (Table C2). Summer, autumn and winter temperatures increased across all forest systems, except autumn Tmin in the 'Douglas fir - Massif Central' system. Regarding water constraints, spring precipitation decreased, except for Scots and Corsican pine in the Northern plains and for Norway spruce and European larch in the Alps (Table C2). Summer precipitations decreased across all forest systems, except for Scots pine and European larch in the Alps and for Aleppo pine in the Mediterranean. Autumn precpitations increased, except for Norway spruce and Silver fir in the Vosges, Maritime and Cosrican pine in the Northern plains, and Maritime pine in the south west region. Winter precpitations increased across all forest systems (Table C2). In summary, across most forest systems (1) temperatures have increased in all but spring seasons, and (2) seasonal precipitations have decreased in spring and summer, have shown divergent trends in autumn and have increased in winter.

From an origin perspective, native systems were located in regions of significantly $(P<0.1)$ lower temperatures (annual and all seasonal but summer; Fig. C17) and undergoing significantly stronger warming in annual (Tmin and Tmean), spring (Tmin, Tmean and Tmax) 
and summer (Tmin and Tmean) temperatures and weaker winter warming (Tmax; Fig. C18). Native regions presented significantly greater autumn precipitation with stronger positive trends than introduced regions (Fig. C18).

\subsection{Relationships between growth trends and contemporary climatic trends and local} growing environment across forest systems

\subsubsection{Univariate regression analyses}

Significant $(P<0.05)$ antagonist effects of trends in temperature on growth trends were identified, suggesting that both lower and upper growth boundaries were affected by climate across all forest systems. We hence identified a positive effect of decreasing spring temperature (Tmin, Tmean and Tmax), antagonist effects of increasing summer temperatures (positive for Tmin and negative for Tmax), a negative effect of increasing winter temperatures (Tmin, Tmean and Tmax), and a negative effect of increasing mean annual maximum temperature (Table 3 and Fig. 5).

Growth trends were significantly $(P<0.05)$ and positively associated with numerous precipitation variables (average autumn sums, and trends in annual, summer and, autumn sums, Table 3 and Fig. 5), highlighting the role of water constraints on growth trends. Significant correlations were also observed with the average Gini index (positive, i.e. the lower the competition pressure on target dominant trees was, the more positive the growth trend was) and with average soil conditions (including positive effects of soil $\mathrm{pH}$ and base cation availability, and negative effects of field capacity and temporary water-logging; Table

\section{3 and Fig. E2).}

The tree species origin in the forest systems under study was significantly $(P<0.05)$ associated with growth trends, with native forest systems presenting generally positive growth 
trends on average and introduced ones showing mainly negative trends (Table 3 and Fig. 4A).

Growth trends were also significantly $(P<0.05)$ associated with elevation (positive) and, to a lesser extent $(P<0.1)$ with permanent water-logging (negative) and soil carbon-to-nitrogen ratio (positive) (Table 3).

\subsubsection{Bivariate regression analyses}

The antagonist effects of temperature, regardless of the variables chosen, remained both significant in a bivariate model (Tables 4 \& F1 in Appendix F and Fig. E3.A). These results supported the hypothesis $\mathbf{H 1}$ according to which trends in temperature can simultaneously positively and negatively affect radial growth depending on whether the climate variable corresponds to growth constraint (e.g. inhibition of cambium activity through too cold spring temperature) or a physiological margin (e.g. temperature threshold above which water demands to maintain photosynthesis processes can't be met, inducing important physiological damages like embolism).

The effects of precipitation and temperature variables remained only simultaneously significant in a bivariate model when the effects of all climate variables were positive, i.e. only when trends in precipitation and temperature had a positive effect on radial growth. The positive effect of trends in summer precipitation (the less negative the trend, the greater growth) and decreasing spring temperature (Tmin, Tmean, or Tmax) coexisted when included in the same model (Tables 4 \& F2 and Fig. E3.B). The positive effects of both the average and trend in mean autumn precipitation, on one side, coexisted with the negative effect of increasing summer maximum temperature, on the other side. However, the positive effects of precipitations (regardless of the variables used) overrode the negative effect of increasing winter temperature when combined in a same regression model, the latter turning insignificant (Tables 4 \& F2). These observations were consistent with the hypothesis $\mathbf{H 2}$ according to 
which water is constraining growth across forest systems, particularly when increases in temperature are exacerbating such constraint.

The positive effect of tree-to-tree competition (Gini index) coexisted in bivariate models with the positive effect of the carbon-to-nitrogen ratio $(P<0.05)$, and to some extent $(P<0.1)$ with the positive effects of trends in summer precipitation, soil $\mathrm{pH}$ and base cation availability (Tables 4 \& F3 and Figs. 4D \& E3C-D). This coexistence supported the hypothesis H3 stipulating that tree growth responses reflect tree-to-tree competition for water and nutrient resources.

\subsubsection{Multivariate analyses}

The coexistence of more than two significant variables $(P<0.05)$ in a model was never observed, possibly due to the restricted number of observations (16 forest systems). When combining temperature variables showing positive and negative effects on tree growth (a random combination of two variables of each category) and any precipitation variable into a single linear model, the temperature variable with a positive effect on growth trends was the sole to remain significant (Tables 4 \& F4).

Similarly, when combining the significant positive effects of decreasing spring temperatures, of the trend in summer precipitation and, of the Gini index, the sole remaining significant effect was the positive effect of trends in summer precipitation (the less negative the trend, the greater the growth) (Tables $4 \mathbf{\&} \mathbf{F 4})$. When the trends in summer maximum temperature (positive effect) was added to this three-variable model, the only significant effect left was instead the trend in spring temperature (negative), regardless of the temperature variable chosen (i.e. spring Tmin, Tmean or Tmax). The positive effect of the Gini index only coexisted with the positive effect of decreasing spring temperature and the negative effect of increasing maximum summer temperature although most effects were not significant $(P>$ 0.05) (Tables 4 \& F4). 
When combined with major abiotic and biotic predictors of growth trends, the significant effect of the origin of tree species coexisted significantly $(P<0.05)$ with the negative effects of increases in winter minimum temperature and in mean annual and summer maximum temperatures, with the positive effect of the carbon-to-nitrogen ratio and, to some extent with the positive effects of trends in summer precipitation $(P<0.1)$ (Tables $4 \boldsymbol{\&}$ F5). Of note, no significant collinearity between the tree species origin variable and each of these five variables was identified (Table F5). This result support the hypothesis $\mathbf{H 4}$ according to which forest systems based on introduced conifer tree species are more prone to growth decline in the face of climatic change than those based on native tree species.

\subsubsection{Summary}

Regression analyses evidenced that (i) the major antagonist effects of temperature on tree growth trends were the positive effect of decreasing spring temperature and the negative effects of increasing winter (Tmin, Tmean, Tmax) and summer (Tmax) temperatures (hypothesis H1). These latter negative effects clearly indicate that the optimal growing climate for conifer species is constrained within a range of minimum and maximum temperatures (i.e. winter and summer seasons) and that when their growing climate envelope is translated towards warmer ranges, it is detrimental to growth; (ii) most averages and trends in seasonal precipitation variables positively correlated with growth trends (hypothesis H2). These positive effects of precipitation mainly coexisted with the positive, rather than with the negative, effects of temperature; (iii) more heterogeneous stand structure had a positive effect on growth trends and this positive effect coexisted with the positive effects of soil water and nutrient resources (hypothesis H3); (iv) when comparing major temperature, precipitation and tree-to-tree competition constraints on growth trends, only one factor remained significant, either the trend in summer precipitation or the trend in spring temperature (both having positive effects on growth); (v) remarkably, growth in native forest systems appeared 
to be more resilient to trends in summer maximum temperature and precipitation than in introduced systems (hypothesis H4), supporting the hypothesis of an increasing competition pressure under climate change.

\section{Discussion}

\subsection{The French NFI, a powerful monitoring system of climate change impacts on forests}

Over the 11-year period of the continuous French NFI, reliable and spatially-coherent tree growth trends were captured across a wide variety of forest ecosystems and bioclimatic contexts owing to the high amount of data available ( $>10,000$ tree-ring measurements). The strength of NFI not only emerges from their unbiased statistical design but also from the exhaustive auxiliary and environmental plot data they collect. These data allow accounting for a large panel of environmental variables and their spatiotemporal variability in the modeling of inter-annual radial growth variability. Such exhaustive information on forest growing conditions is a key to unravel interactions between abiotic and biotic factors in shaping tree growth patterns and to better isolate the sole effects of climate on tree growth. Data from the French NFI however presents some limitations, including the temporal depth of tree-ring measurements that will however continuously increase in time, and as such is not limiting for the development of a continuous monitoring system of forest growth. Given that the eight conifer tree species herein studied are substantially prevalent across European forests and that pure and even-aged forests have become increasingly used in forestry practices, the present methodology could be adapted and applied to other European NFI thanks to ongoing panEuropean harmonization efforts in terms of NFI (Gschwantner et al., 2016).

\subsection{Annual growth measurement accuracy and trend detection}


With measurements performed in the field, potential bias may exist in terms of tree-ring measuring and positioning (e.g. missing ring or false ring). Nevertheless such source of bias has been limited through (i) the selection of dominant conifer trees that usually present clear and wide tree-rings, and (ii) by inquiring the first completed tree-ring from the bark. Second, the value of annual radial growth anomalies herein reported ranged between $-0.5 \mathrm{~mm}$ and +2 $\mathrm{mm}$ of the 2006 reference growth level, which remains 5 to $20 \%$ times greater than the resolution of field measurements $(0.1 \mathrm{~mm})$. This clearly demonstrates that measuring errors, if present, remain negligible compared to the magnitude of the herein reported growth trends. NFI data, although poorly replicated at the tree and plot level, are extensively replicated through space and time and by definition statistically unbiased (Duchesne et al., 2017; Klesse et al., 2018). The consistency of the herein presented results demonstrates that huge datasets derived from gridded statistical designs can serve as a robust and trend-sensitive monitoring of forest growth, even over restricted time periods. The significance of the calendar year variable in almost all models further underlines the capacity of NFI-based tree-growth modeling to detect inter-annual variability in tree growth over a short period and across various conifer forest systems.

\subsection{Thermic and geographical gradients behind the variability of observed growth trends}

Tree growth trends were structured along a thermic gradient and related to the tree species origin of forest systems (hypotheses H1 \& H4). The growth trends of a given tree species aligned along elevation (e.g. Scots pine and Norway spruce) or latitudinal (e.g. maritime pine, Aleppo pine) gradients, with more positive trends being observed at the colder end of each gradient (either in regions of high altitudes or latitudes). These results are consistent with observations reported in Charru et al. (2017) on broadleaved and coniferous tree species across France whereby tree growth trends were strongly structured along a temperature 
gradient, trends ranging from $+42 \%$ in cold mountainous regions and $-17 \%$ in warm Mediterranean areas. Conifer tree species also appeared noticeably more resilient to climate change in regions where they are naturally encountered, with growth trends of native forest systems being mostly positive and those of introduced systems being mainly negative. Conifer species naturally encountered in cold environment (e.g. Norway spruce) have mostly been introduced in warmer contexts such as lower elevation mountain ranges or plains. Not surprisingly, these cold-adapted species presented stronger growth releases in cooler native regions than in warmer introduced ones (e.g. Alpine context vs. northern plains). On the opposite, conifer species naturally encountered in warm regions (all pine species except Scots pine) presented more positive trends in introduced contexts than in native ones (e.g. maritime and Corsican pine in the northern plains). These warm-adapted species have mostly been introduced in more northern contexts and appear clearly favored by these new cooler contexts. At first glance, the discernible association between species' origin and their growth trends might therefore arise from a thermal effect on tree growth, with the cooler environment the better, regardless of the drought-tolerance of a tree species. This conclusion is also consistent with within-tree species responses observed along elevation or latitudinal gradients in France (e.g. Scots pine, Norway spruce, and maritime pine; but see also the discussion below regarding the collinearity between tree species origin and the Gini index).

\subsection{Non-uniform impacts of trends in temperature on tree growth across seasons}

Beyond the overall benefits of cooler environments on tree growth, the herein observed antagonist effects of temperature on growth trends demonstrate however that the impacts of trends in temperature on forest systems are non-uniform across seasons (Wilmking et al., 2004). The positive effect of decreasing spring temperature (Tmin, Tmean and Tmax) might underline that the greater the spring temperatures (on absolute scale), the better for tree 
growth. Cooler spring might delay the start of the growing season and decrease growth potential. In a period where summer droughts have been occurring earlier and with greater intensity (Buras et al., 2019), such a delay might also expose trees to increased water demand and physiological risks during the early stages of the xylogenesis (e.g. cavitation due to a high water demand in a warmer early summer climate). In Alpine forest systems, the positive effect of the trend in spring temperature may rather emerge from an alleviation of growthlimitation by cool temperatures at the beginning of the growing season. Indeed, these systems where the only ones to undergo an increase in spring temperature (Tmax) over the study period and presented the strongest growth releases observed. Warmer springs have been reported to trigger an earlier start of the growing season and to stimulate growth rate, particularly in cold environments (Rossi et al., 2014; Wilmking et al., 2004).

\subsection{The narrow optimal temperature range for conifer tree growth}

The negative impact of growing-season temperatures on tree growth was underlined by the negative effect of increasing summer maximum temperature. Summer maximum temperatures represent the warmest climate trees face within a year. These temperatures have been increasing at paces ranging between $+0.05^{\circ} \mathrm{C}$ (in the Alps) and $+0.16^{\circ} \mathrm{C}$ (in the Vosges) per year, challenging forests' physiological tolerance to warmth. Trends in winter temperature, positive over the study period across all forest systems, were also clearly associated with greater growth decreases. Warmer winters have been shown to disturb dormancy conditions and phenological cycles (e.g. spring resumption of cambium and bud break) through inadequate chilling (Dantec et al., 2014; Delpierre et al., 2019). Conifer species native from cold environments have developed physiological needs of long and cold dormancy period (Smith and Hinckley, 1995). Our results underline that conifers are negatively responding to climate warming during both the hotter period of the growing season (summer maximum 
temperature) and during the non-growing season (winter). The optimal growth of conifers hence appears to be constrained by a climatic envelope with cold- and warm-season upper bounds that cannot be passed without detrimental effects on growth. This is also consistent with growth trends being systematically more positive in cooler regions such as higher elevations (e.g. Norway spruce and Scots pine) or northern distribution margins (e.g. maritime pine, Aleppo pine and Corsican pine). Given that the negative effects of summer and winter warming were observed over a period where these variables presented insignificant trends, our results underline that detrimental effects of climate change on tree growth dynamics may emerge long before trends in climate become significant. With the prediction of continuously increasing temperatures (IPCC, 2014), the tree growth potential of diverse forest ecosystems might decrease faster than previously thought.

\subsection{Water availability, a key determinant of future forest vitality}

In the face of a generalized warming, water is also confirmed to be a key determinant of growth potential. Our study adds up to the growing number of literature pointing at an increasing control of precipitation upon tree growth across the globe (Babst et al., 2019). Also, the modulation of growth response to trends in temperature by water availability was observed in Charru et al. (2017) over a more ancient growth period. This suggests that the interplay between temperature effect and water availability is a key and long-lasting determinant to forest vitality. In the present study, we not only captured the positive effect of recent precipitation increases (up to $+60 \mathrm{~mm}$ over 10 years) but also the negative effect of decreasing precipitations on tree growth (down to - $90 \mathrm{~mm}$ over 10 years). Regardless of the climate type (oceanic, continental, Mediterranean or mountainous), decreases in precipitations were systematically detrimental to growth. Interestingly, most growth declines were observed in regions where average growing conditions appeared optimal (e.g. high level of 
precipitation, high water field capacity, good soil fertility) but where precipitation levels have decreased. This somehow counter-intuitive observation highlights that good average growing conditions do not preclude forest systems from physiological stress (e.g. Trouvé, Bontemps, Collet, Seynave, \& Lebourgeois, 2017) and may instead exacerbate it and prevent tree growth acclimation to more detrimental contexts. Forest systems growing under optimal conditions, e.g. sufficient water resources, might be more sensitive to decreases in water inputs, even marginal ones, than forests growing in suboptimal conditions (McNulty et al., 2014). As a matter of fact, the strongest growth releases were observed in native forest systems with suboptimal growing conditions (low level of precipitation, low field capacity, and low soil fertility) but where precipitations have increased. Shifts in growing conditions (from optimal to suboptimal and vice versa) hence appear also associated with trends in precipitation regimes.

\subsection{More heterogeneous forest structures in favor of conifer tree growth}

In the face of climate change, a more heterogeneous stand structure was also strongly associated with a greater growth trend. In pure and even-aged conifer forests, a more heterogeneous structure could favor the growth of dominant trees by increasing their social dominance and favoring their access to light and nutrient resources. This would also support that at constant precipitation regimes, a slightly more heterogeneous stem size distribution increases the growth potential of dominant trees and that greater growth trends were observed in heterogeneous native forests rather than in homogeneous introduced forests. Strongly associated with the type of forest systems (native or introduced), stand structure appears to favor the resilience of dominant-tree growth to climate change which points out to the importance of forest management orientation (Brang et al., 2014). Forest management could 
hence compensate for decreasing water resources by promoting more heterogeneous stand structure.

\section{Conclusions}

- The growth of conifer tree species appears to be bounded by a narrow thermic envelope in Western Europe and constrained by water availability, particularly in lowelevation contexts where they have been introduced through afforestation program. While warming at the beginning of the growing season may stimulate tree growth, warmer summers and winters are pushing forest systems towards physiological edges and increasing needs for water.

- A positive effect of a more heterogeneous stand structure on growth trends is demonstrated. This effect remains significant when tested for confusion against the herein-evidenced major climatic drivers of forest growth indicating that forest management has a role to play in increasing the resilience of coniferous forests in the face increasing thermal and water constraints.

- The greater heterogeneity of native forest systems, as compared to introduced systems, for a given tree species appears to be an emergent property enhancing resilience against climate change. It follows that modern homogenous plantations, exotic species and foreign populations may not be the most resilient to future climates in spite of the efforts and costs consented in afforestation programs (FFN or National Forest Fund in France). The issue is crucial and deserves further exploration as modern conifer plantations have become increasingly common in silvicultural practices across temperate and boreal biomes during the past century.

- National forest inventories can serve as promising continuous monitoring systems of tree growth across various forest types. The adaptation and generalization of the 
present methods to other NFIs in Europe would support a more integrative continental monitoring strategy, in line with current bioeconomy strategies. Future steps will build on the emerging pan-European harmonization effort on forest increment (Gschwantner et al., 2016).

\section{CRediT authorship contribution statement}

Clémentine Ols: Formal analysis, Funding acquisition, Methodology, Project administration, Writing - original draft, Writing - review and editing.

Jean-Christophe Hervé: Conceptualization, Data curation.

Jean-Daniel Bontemps: Conceptualization, Data curation, Funding acquisition, Methodology, Project administration, Supervision, Writing - original draft, Writing - review and editing.

\section{Declaration of interests}

The authors declare no competing interest.

\section{Acknowledgements}

This study was supported by a grant ('Growth of European Coniferous Forests under Climate Change' project) overseen by the French National Research Agency (ANR) as part of the “Investissements d'Avenir" program (ANR-11-LABX-0002-01, Laboratory of Excellence ARBRE) and by the Région Grand Est ('Growth of European Coniferous Forests in a Context of Climate Change' project). This project was also partially supported by the French PIA project “Lorraine Unviersité d'Excellence” (ANR-15-IDEX-04-LUE). We acknowledge the E-OBS dataset from the EU-FP6 project UERRA (http://www.uerra.eu) and the Copernicus Climate Change Service, and the data providers in the ECA\&D project (https://www.ecad.eu). We are thankful to Ingrid Seynave and Emilien Kunz for the extraction of ground-flora based 
soil variables and to Emeline Chaste for technical support regarding the extraction of climate data.

\section{References}

Aguirre, A., del Río, M., Condés, S., 2019. Productivity Estimations for Monospecific and Mixed Pine Forests along the Iberian Peninsula Aridity Gradient. Forests 10. https://doi.org/10.3390/f10050430

Andersson, F.A., 2005. Ecosystems of the world - Coniferous forests, Elsevier Science. ed. Netherlands.

Babst, F., Bodesheim, P., Charney, N., Friend, A.D., Girardin, M.P., Klesse, S., Moore, D.J.P., Seftigen, K., Björklund, J., Bouriaud, O., Dawson, A., DeRose, R.J., Dietze, M.C., Eckes, A.H., Enquist, B., Frank, D.C., Mahecha, M.D., Poulter, B., Record, S., Trouet, V., Turton, R.H., Zhang, Z., Evans, M.E.K., 2018. When tree rings go global: Challenges and opportunities for retro- and prospective insight. Quaternary Science Reviews 197, 1-20. https://doi.org/10.1016/j.quascirev.2018.07.009

Babst, F., Bouriaud, O., Poulter, B., Trouet, V., Girardin, M.P., Frank, D.C., 2019. Twentieth century redistribution in climatic drivers of global tree growth. Science Advances 5, eaat4313. https://doi.org/10.1126/sciadv.aat4313

Barbati, A., Corona, P., Marchetti, M., 2007. A forest typology for monitoring sustainable forest management: The case of European Forest Types. Plant Biosystems - An International Journal Dealing with all Aspects of Plant Biology 141, 93-103. https://doi.org/10.1080/11263500601153842

Björklund, J., Seftigen, K., Schweingruber, F., Fonti, P., von Arx, G., Bryukhanova, M.V., Cuny, H.E., Carrer, M., Castagneri, D., Frank, D.C., 2017. Cell size and wall dimensions drive distinct variability of earlywood and latewood density in Northern Hemisphere conifers. New Phytologist 216, 728-740. https://doi.org/10.1111/nph.14639

Bontemps, J.-D., Bouriaud, O., 2014. Predictive approaches to forest site productivity: recent trends, challenges and future perspectives. Forestry: An International Journal of Forest Research 87, 109-128. https://doi.org/10.1093/forestry/cpt034

Bontemps, J.-D., Hervé, J.-C., Denardou, A., 2019. Partition idéalisée et régionalisée de la composition en espèces ligneuses des forêts françaises. Écoscience 26, 291-308. https://doi.org/10.1080/11956860.2019.1588511

Box, G.E.P., Cox, D.R., 1964. An Analysis of Transformations. Journal of the Royal Statistical Society: Series B (Methodological) 26, 211-243. https://doi.org/10.1111/j.2517-6161.1964.tb00553.x

Brang, P., Spathelf, P., Larsen, J.B., Bauhus, J., Boncčìna, A., Chauvin, C., Drössler, L., García-Güemes, C., Heiri, C., Kerr, G., Lexer, M.J., Mason, B., Mohren, F., Mühlethaler, U., Nocentini, S., Svoboda, M., 2014. Suitability of close-to-nature silviculture for adapting temperate European forests to climate change. Forestry: An International Journal of Forest Research 87, 492-503. https://doi.org/10.1093/forestry/cpu018

Buras, A., Rammig, A., Zang, C.S., 2019. Quantifying impacts of the drought 2018 on European ecosystems in comparison to 2003. Biogeosciences Discuss. 2019, 1-23. https://doi.org/10.5194/bg-2019-286

Cavaignac, S., 2009. Les sylvoécorégions (SER) de France méropolitaine. Etude de définition. Inventaire Forestier National, Nogent-sur-Vernisson.

Charru, M., Seynave, I., Hervé, J.-C., Bertrand, R., Bontemps, J.-D., 2017. Recent growth changes in Western European forests are driven by climate warming and structured across tree species 
climatic habitats. Annals of Forest Science 74, 33. https://doi.org/10.1007/s13595-017-06261

Charru, M., Seynave, I., Hervé, J.-C., Bontemps, J.-D., 2013. Spatial patterns of historical growth changes in Norway spruce across western European mountains and the key effect of climate warming. Trees 28, 205-221. https://doi.org/10.1007/s00468-013-0943-4

Cornes, R.C., van der Schrier, G., van den Besselaar, E.J.M., Jones, P.D., 2018. An Ensemble Version of the E-OBS Temperature and Precipitation Data Sets. Journal of Geophysical Research: Atmospheres 123, 9391-9409. https://doi.org/10.1029/2017JD028200

Dantec, C.F., Vitasse, Y., Bonhomme, M., Louvet, J.-M., Kremer, A., Delzon, S., 2014. Chilling and heat requirements for leaf unfolding in European beech and sessile oak populations at the southern limit of their distribution range. Int J Biometeorol 58, 1853-1864. https://doi.org/10.1007/s00484-014-0787-7

Delpierre, N., Lireux, S., Hartig, F., Camarero, J.J., Cheaib, A., Čufar, K., Cuny, H., Deslauriers, A., Fonti, P., Gričar, J., Huang, J.-G., Krause, C., Liu, G., de Luis, M., Mäkinen, H., del Castillo, E.M., Morin, H., Nöjd, P., Oberhuber, W., Prislan, P., Rossi, S., Saderi, S.M., Treml, V., Vavrick, H., Rathgeber, C.B.K., 2019. Chilling and forcing temperatures interact to predict the onset of wood formation in Northern Hemisphere conifers. Global Change Biology 25, 1089-1105. https://doi.org/10.1111/gcb.14539

Duchesne, L., D'Orangeville, L., Ouimet, R., Houle, D., Kneeshaw, D., 2017. Extracting coherent treering climatic signals across spatial scales from extensive forest inventory data. PLOS ONE 12, e0189444. https://doi.org/10.1371/journal.pone.0189444

Dunson, W.A., Travis, J., 1991. The Role of Abiotic Factors in Community Organization. The American Naturalist 138, 1067-1091.

Ellenberg, H., 2009. Vegetation Ecology of Central Europe, 4th ed. Cambrigde University Press.

Fischer, C., 2016. Comparing the Logarithmic Transformation and the Box-Cox Transformation for Individual Tree Basal Area Increment Models. Forest Science 62, 297-306. https://doi.org/10.5849/forsci.15-135

Gégout, J.-C., 2006. Distribution et caractère bioindicateur des espèces végétales forestières françaises vis-à-vis du sol et du climat. (Habilitation à Diriger des Recherches de l'Institut Polytechnique de Lorraine, spécialité: Sciences Agronomiques). Ecole Nationale du Génie Rural des Eaux et des Forêts (ENGREF), Nancy.

Girardin, M.P., Bouriaud, O., Hogg, E.H., Kurz, W., Zimmermann, N.E., Metsaranta, J.M., de Jong, R., Frank, D.C., Esper, J., Buntgen, U., Guo, X.J., Bhatti, J., 2016. No growth stimulation of Canada's boreal forest under half-century of combined warming and $\mathrm{CO} 2$ fertilization. Proc. Natl. Acad. Sci. U. S. A. 113, E8406-E8414. https://doi.org/10.1073/pnas.1610156113

Grissino-Mayer, H.D., Fritts, H.C., 1997. The International Tree-Ring Data Bank: an enhanced global database serving the global scientific community. The Holocene 7, 235-238. https://doi.org/10.1177/095968369700700212

Gschwantner, T., Lanz, A., Vidal, C., Bosela, M., Di Cosmo, L., Fridman, J., Gasparini, P., Kuliešis, A., Tomter, S., Schadauer, K., 2016. Comparison of methods used in European National Forest Inventories for the estimation of volume increment: towards harmonisation. Annals of Forest Science 73, 807-821. https://doi.org/10.1007/s13595-016-0554-5

Hervé, J.-C., 2016. National Forest Inventories Reports - France, in: National Forest Inventories Assessment of Wood Availability and Use. Vidal et al., pp. XXXII, 845.

Housset, J.M., Nadeau, S., Isabel, N., Depardieu, C., Duchesne, I., Lenz, P., Girardin, M.P., 2018. Tree rings provide a new class of phenotypes for genetic associations that foster insights into adaptation of conifers to climate change. New Phytologist 218, 630-645. https://doi.org/10.1111/nph.14968

Ibáñez, B., Ibáñez, I., Gómez-Aparicio, L., Ruiz-Benito, P., García, L.V., Marañón, T., 2014. Contrasting effects of climate change along life stages of a dominant tree species: The importance of soilclimate interactions. Divers. Distrib. 20, 872-883. https://doi.org/10.1111/ddi.12193 
IGN, 2018. Le mémento inventaire forestier. Institut National de l'Information Géographique et Forestière.

IPCC, 2014. Intergovernmental Panel on Climate Change. Fifth assessment report climate change 2014. synthesis report---summary for policymakers 1-35.

Kauppi, P.E., Posch, M., Pirinen, P., 2014. Large Impacts of Climatic Warming on Growth of Boreal Forests since 1960. PLOS ONE 9, e111340. https://doi.org/10.1371/journal.pone.0111340

Klesse, S., DeRose, R.J., Guiterman, C.H., Lynch, A.M., O'Connor, C.D., Shaw, J.D., Evans, M.E.K., 2018. Sampling bias overestimates climate change impacts on forest growth in the southwestern United States. Nature communications 9, 5336. https://doi.org/10.1038/s41467-018-07800-y

Kuhn, E., 2016. Expansion et régression des espèces végétales forestières en contexte de changement climatique (Thèse de doctorat, spécialité: Sciences Forestières. Ecole doctorale RP2E). AgroParisTech, Nancy.

Lévesque, M., Saurer, M., Siegwolf, R., Eilmann, B., Brang, P., Bugmann, H., Rigling, A., 2013. Drought response of five conifer species under contrasting water availability suggests high vulnerability of Norway spruce and European larch. Global Change Biology 19, 3184-3199. https://doi.org/10.1111/gcb.12268

McNulty, S.G., Boggs, J.L., Sun, G., 2014. The rise of the mediocre forest: Why chronically stressed trees may better survive extreme episodic climate variability. New For 45, 403-415. https://doi.org/10.1007/s11056-014-9410-3

Mérian, P., Bontemps, J.-D., 2014. Modèles d'impact climatique pour la productivité et la probabilité de présence d'espèces ligneuses principales de la forêt française. ANR Oracle, Nancy.

Morneau, F., Duprez, C., Hervé, J.-C., 2008. Les forêts mélangées en France métropolitaine. Caractérisation à partir des résultats de l'Inventaire Forestier National. Rev For Fr 60, 107120.

Navarro-Cerrillo, R.M., Sánchez-Salguero, R., Manzanedo, R.D., Camarero, J.J., Fernández-Cancio, Á., 2014. Site and age condition the growth responses to climate and drought of relict Pinus nigra subsp. salzmannii populations in southern Spain. Tree-Ring Res 70, 145-155. https://doi.org/10.3959/1536-1098-70.2.145

Ols, C., Trouet, V., Girardin, M.P., Hofgaard, A., Bergeron, Y., Drobyshev, I., 2018. Post-1980 shifts in the sensitivity of boreal tree growth to North Atlantic Ocean dynamics and seasonal climate. Global Planet. Change 165, 1-12. https://doi.org/10.1016/j.gloplacha.2018.03.006

R Core Team, 2015. R: A language and environment for statistical computing. R Foundation for Statistical Computing, Vienna, Austria. IURL http://www.R-project.org/.

Reineke, L.H., 1933. Perfecting a stand-density index for even-aged forests. Journal of Agricultural Research 46, 627-638.

Rossi, S., Girard, M.J., Morin, H., 2014. Lengthening of the duration of xylogenesis engenders disproportionate increases in xylem production. Global Change Biol. 20, 2261-71. https://doi.org/10.1111/gcb.12470

Schütz, J.P., 1975. Dynamique et conditions d'équilibre de peuplements jardinés sur les stations de la hêtraie à sapin 637-671.

Seftigen, K., Frank, D.C., Björklund, J., Babst, F., Poulter, B., 2018. The climatic drivers of normalized difference vegetation index and tree-ring-based estimates of forest productivity are spatially coherent but temporally decoupled in Northern Hemispheric forests. Global Ecology and Biogeography 27, 1352-1365. https://doi.org/10.1111/geb.12802

Skovsgaard, J.P., Vanclay, J.K., 2007. Forest site productivity: a review of the evolution of dendrometric concepts for even-aged stands. Forestry: An International Journal of Forest Research 81, 13-31. https://doi.org/10.1093/forestry/cpm041

Smith, W.K., Hinckley, T.M. (Eds.), 1995. Front Matter, in: Ecophysiology of Coniferous Forests. Academic Press, San Diego, p. iii. https://doi.org/10.1016/B978-0-08-092593-6.50002-5

Solomon, D.L., 1975. A Note on the Non-equivalence of the Neyman-Pearson and Generalized Likelihood Ratio Tests for Testing a Simple Null versus a Simple Alternative Hypothesis. The American Statistician 29, 101-102. https://doi.org/10.1080/00031305.1975.10477383 
Tomppo, E., Gschwantner, T., Lawrence, M., McRoberts, R.E., 2010. National Forest Inventories Pathways for Common Reporting, 1st ed. Springer Netherlands.

Trouvé, R., Bontemps, J.-D., Collet, C., Seynave, I., Lebourgeois, F., 2017. Radial growth resilience of sessile oak after drought is affected by site water status, stand density, and social status. Trees 31, 517-529. https://doi.org/10.1007/s00468-016-1479-1

Venables, W.N., Ripley, B.D., 2002. Modern Applied Statistics with S, 4th ed. Springer-Verlag New York.

Vidal, C., Alberdi, I., Hernandez, L., Redmond, J., 2016. National Forest Inventories - Assessment of Wood Availability and Use, 1st ed. Springer International Publishing Switzerland.

Waring, R., Nordmeyer, A., Whitehead, D., Hunt, J., Newton, M., Thomas, C., Irvine, J., 2008. Why is the productivity of Douglas-fir higher in New Zealand than in its native range in the Pacific Northwest, USA? Forest Ecology and Management 255, 4040-4046. https://doi.org/10.1016/j.foreco.2008.03.049

Wilmking, M., Juday, G.P., Barber, V.A., Zald, H.S.J., 2004. Recent climate warming forces contrasting growth responses of white spruce at treeline in Alaska through temperature thresholds. Glob Chang Biol 10, 1724-1736. https://doi.org/10.1111/j.1365-2486.2004.00826.x

Wu, X., Liu, H., Guo, D., Anenkhonov, O.A., Badmaeva, N.K., Sandanov, D.V., 2012. Growth decline linked to warming-induced water limitation in Hemi-Boreal forests. PLoS One 7. https://doi.org/10.1371/journal.pone.0042619

Zhao, S., Pederson, N., D'Orangeville, L., HilleRisLambers, J., Boose, E., Penone, C., Bauer, B., Jiang, Y., Manzanedo, R.D., 2019. The International Tree-Ring Data Bank (ITRDB) revisited: Data availability and global ecological representativity. Journal of Biogeography 46, 355-368. https://doi.org/10.1111/jbi.13488 


\section{Tables}

Table 1. Forest systems under study and their climatic characteristics. Average annual climate and associated trends were computed over the 2006-2016 period within the geographical extent defined by the plots included in each forest system. Climate variables presented include mean annual precipitation (MAP), and mean annual mean temperature (MAT). Units for precipitation and temperature averages are $\mathrm{mm}$ and ${ }^{\circ} \mathrm{C}$, respectively, and mm. $\mathrm{yr}^{-1}$ and ${ }^{\circ} \mathrm{C} . \mathrm{yr}^{-1}$ for their associated trends. Significant trends $(P<0.1)$ are highlighted in bold. The mean elevation of a forest system is given in meters above sea level by the column Elev. The column Origin indicates whether a forest system was considered as native (Nat.) or introduced (Int.). For more information regarding the geographical location and extent of ecological regions please refer to Fig. S1.

\begin{tabular}{llcccccc} 
& & & & \multicolumn{2}{c}{ MAT } & \multicolumn{2}{c}{ MAP } \\
\cline { 5 - 8 } Tree species & Ecological region & Origin & Elev. [m] & Average & Trend & Average & Trend \\
\hline Douglas-fir & Northern plains & Int. & 242 & 11.2 & 0.03 & 743 & -3.6 \\
Douglas-fir & Massif central & Int. & 638 & 10.6 & 0.04 & 811 & -3.6 \\
Scots pine & Northern plains & Int. & 152 & 11.5 & 0.03 & 685 & -0.8 \\
Scots pine & Massif Central & Nat. & 938 & 9.3 & 0.05 & 820 & -2.6 \\
Scots pine & Alps & Nat. & 1117 & 9.4 & 0.04 & 874 & $\mathbf{1 5 . 5}$ \\
Norway spruce & Northern plains & Int. & 327 & 10.2 & 0.04 & 841 & -11.4 \\
Norway spruce & Vosges & Nat. & 631 & 9.7 & 0.07 & 839 & -9.8 \\
Norway spruce & Massif central & Int. & 951 & 9.6 & 0.04 & 826 & -3.8 \\
Norway spruce & Alps & Nat. & 1365 & 7.0 & 0.05 & 1090 & $\mathbf{1 9 . 2}$ \\
Maritime pine & Northern plains & Int. & 92 & 12.2 & 0.04 & 688 & -1.1 \\
Maritime pine & Oceanic south-west & Int. & 63 & 14.0 & 0.06 & 834 & -0.1 \\
Silver fir & Vosges & Nat. & 579 & 9.7 & 0.07 & 807 & -10.1 \\
Silver fir & Massif central & Nat. & 961 & 9.8 & 0.05 & 789 & -4.5 \\
Corsican pine & Northern plains & Int. & 123 & 11.8 & 0.03 & 681 & -1.3 \\
European larch & Alps & Nat. & 1843 & 5.6 & 0.03 & 1084 & $\mathbf{1 9 . 8}$ \\
Aleppo pine & Mediterranean & Nat. & 252 & 14.4 & 0.05 & 614 & 9.7 \\
\hline
\end{tabular}


Table 2. Statistical overview of the regional growth models. All models are based on a Box-Cox transformation of the independent radial increment data. Obs. - total number of radial increment measurements included in each model; $\lambda$-optimal Box-Cox power transformation parameter; Adj. $\mathrm{R}^{2}$ - adjusted $\mathrm{R}^{2}$; Year effect - significance of the variable 'Year' in the model. Trend - Linear trend in radial growth anomaly chronologies over the 2006-2016 period estimated by the slope of a linear regression and given in $\%$; Tr. $P$ value -

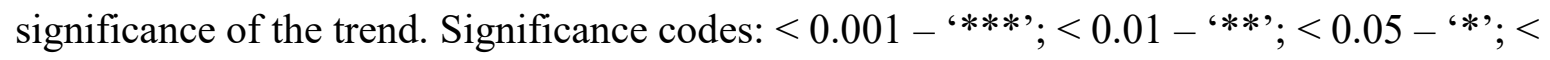
0.1 - '-'; $\geq 0.1$ - 'n.s.'. Significant growth trends $(P<0.05)$ are highlighted in bold. For more information regarding the geographical location and extent of ecological regions please refer to Fig. S1.

\begin{tabular}{llllllccc} 
Tree species & Ecological region & Model & Obs. & $\lambda$ & Adj. $\mathrm{R}^{2}$ & Year effect & Trend & Tr. $P$ value \\
\hline Douglas-fir & Northern plains & DF-NP & 551 & 0.25 & 0.23 & $* * *$ & -21.8 & - \\
Douglas-fir & Massif central & DF-MC & 1145 & 0.45 & 0.2 & $*$ & $\mathbf{- 1 4 . 4}$ & $*$ \\
Scots pine & Northern plains & SP-NP & 581 & 0.2 & 0.21 & $*$ & 3.3 & n.s. \\
Scots pine & Massif Central & SP-MC & 725 & 0.25 & 0.26 & $* * *$ & 19.8 & n.s. \\
Scots pine & Alps & SP-Alp & 826 & 0.15 & 0.23 & $* * *$ & $\mathbf{6 7 . 4}$ & $* *$ \\
Norway spruce & Northern plains & NS-NP & 337 & 0.3 & 0.17 & $* * *$ & $\mathbf{- 2 9 . 9}$ & $*$ \\
Norway spruce & Vosges & NS-Vos & 303 & 0.2 & 0.27 & $* * *$ & -25.9 & n.s. \\
Norway spruce & Massif central & NS-MC & 730 & 0.3 & 0.14 & $*$ & -16.5 & - \\
Norway spruce & Alps & NS-Alp & 279 & 0.35 & 0.21 & n.s. & -2.1 & n.s. \\
Maritime pine & Northern plains & MP-NP & 602 & 0.25 & 0.19 & $* *$ & 20.5 & n.s. \\
Maritime pine & Oceanic south-west & MP-SW & 2366 & 0.25 & 0.41 & $* * *$ & 6.6 & n.s. \\
Silver fir & Vosges & SF-Vos & 331 & 0.35 & 0.21 & n.s. & 3.6 & n.s. \\
Silver fir & Massif central & SF-MC & 589 & 0.3 & 0.15 & $* *$ & 10.3 & n.s. \\
Corsican pine & Northern plains & CP-NP & 482 & 0.25 & 0.36 & - & -18.9 & n.s. \\
European larch & Alps & EL-Alp & 341 & 0.05 & 0.22 & $*$ & $\mathbf{8 6 . 3}$ & $* *$ \\
Aleppo pine & Mediterranean & AP-Med & 455 & 0.2 & 0.25 & $* * *$ & 47.9 & - \\
\hline
\end{tabular}


Table 3. Environmental attributes significantly associated with $(P<0.1)$ growth trends

over the 2006-2016 period. Associations were tested using univariate linear regression

correlation. Significant positive correlations are identified with $+[P<0.05]$ and $(+)[\mathrm{P}<0.1]$.

Significant negative correlations are identified with $-[P<0.05]$ and $(-)[\mathrm{P}<0.1]$. Correlations with an $\mathrm{R}^{2}$ equal to or greater than 0.5 are highlighted in bold. Significance codes: $<0.001-$ '***; $<0.01-{ }^{\prime * *}$ ' $;<0.05-{ }^{* *}$ ' $;<0.1-{ }^{\prime}-’$

\begin{tabular}{lccc}
\hline Variables & Effect & $\mathrm{R}^{2}$ & $P$ value \\
\hline Temperature constraints & & & \\
Elevation & + & 0.25 & $*$ \\
Trend in spring Tmin & + & 0.46 & $* *$ \\
Trend in spring Tmean & + & 0.43 & $* *$ \\
Trend in spring Tmax & + & 0.37 & $*$ \\
Trend in summer Tmin & + & 0.32 & $*$ \\
Trend in summer Tmax & - & 0.41 & $* *$ \\
Trend in winter Tmin & - & 0.33 & $*$ \\
Trend in winter Tmean & - & 0.45 & $* *$ \\
Trend in winter Tmax & - & 0.47 & $* *$ \\
Trend in annual Tmax & - & 0.31 & $*$ \\
\hline Water constraints & & & \\
Field capacity & - & $\mathbf{0 . 5 2}$ & $* *$ \\
Temporary logging & - & 0.39 & $*$ \\
Permanent logging & $(-)$ & 0.22 & - \\
Autumn Prec & + & $\mathbf{0 . 5 1}$ & $* *$ \\
Trend in annual Prec & + & $\mathbf{0 . 5 5}$ & $* *$ \\
Trend in summer Prec & + & $\mathbf{0 . 6}$ & $* * *$ \\
Trend in autumn Prec & + & 0.48 & $* *$ \\
\hline Nutrional constraints & & & \\
Soil pH & + & $\mathbf{0 . 5 1}$ & $* *$ \\
Soil base cation availability & + & 0.37 & $*$ \\
Soil carbon-to-nitrogen ratio & $(+)$ & 0.21 & - \\
Gini index & + & 0.33 & $*$ \\
\hline Origin & + & 0.29 & $*$ \\
\hline
\end{tabular}


Table 4. Summary of multivariate linear regressions between growth trends and environmental attributes. Significant positive effects are identified with $+[P<0.05]$ and $(+)[P<0.1]$. Significant negative effects are identified with $-[P<0.05]$ and $(-)[P<0.1]$. 'n.s.' stands for nonsignificant effects. Abbreviations: spr. - spring; sum. - summer; win. - winter; Prec - Precipitations; Tmean - mean temperature; Tmin -

minimum temperature; Tmax - maximum temperature. Adj. $\mathrm{R}^{2}$ - adjusted $\mathrm{R}^{2}$. H1 to H4 correspond to the four hypotheses introduced in the Material and methods section. The 'Multivariate' column presents attempts to combine different major growth-controlling variables in a unique model. The complete table of models built for each hypothesis is presented in Appendix F. Significance codes: $<0.001-{ }^{`} * * * ;<0.01-{ }^{\prime} * *$ ’; $<$ 0.05 - '*'.

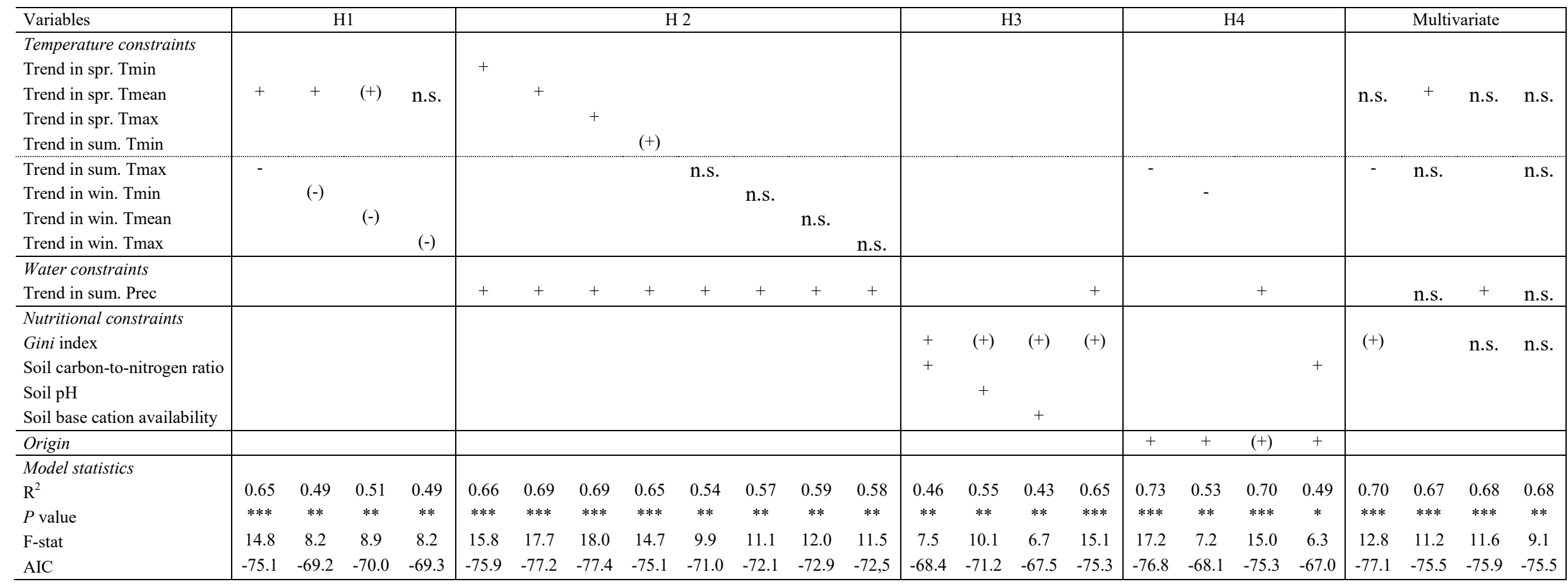


Figures

\section{A. REGIONAL FOREST SYSTEM UNDER STUDY}

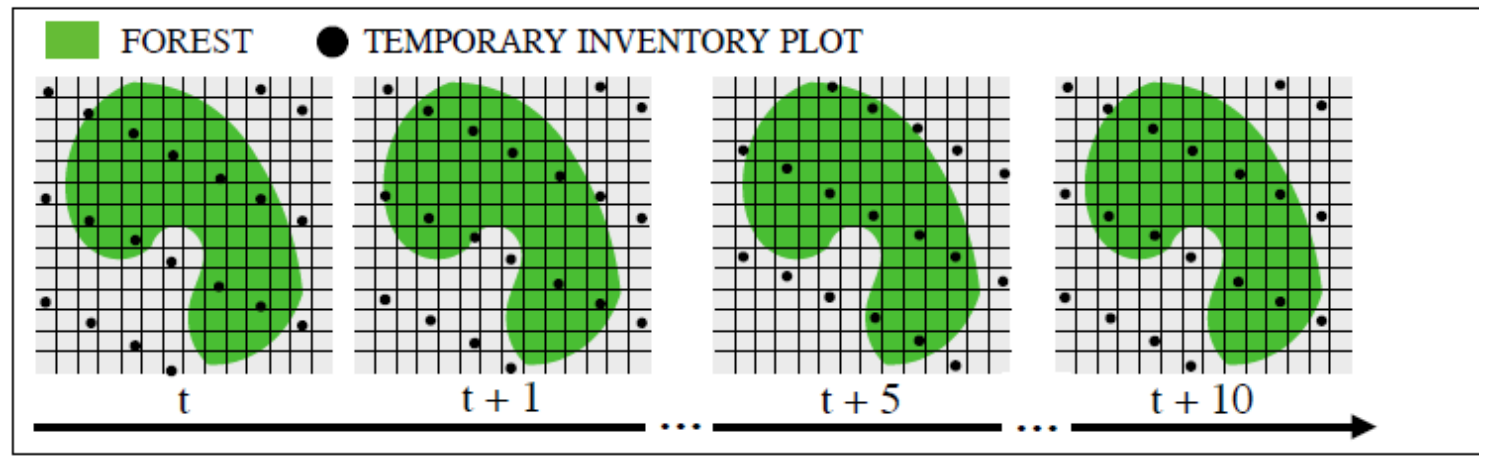

\section{B. MODELING FRAMEWORK}

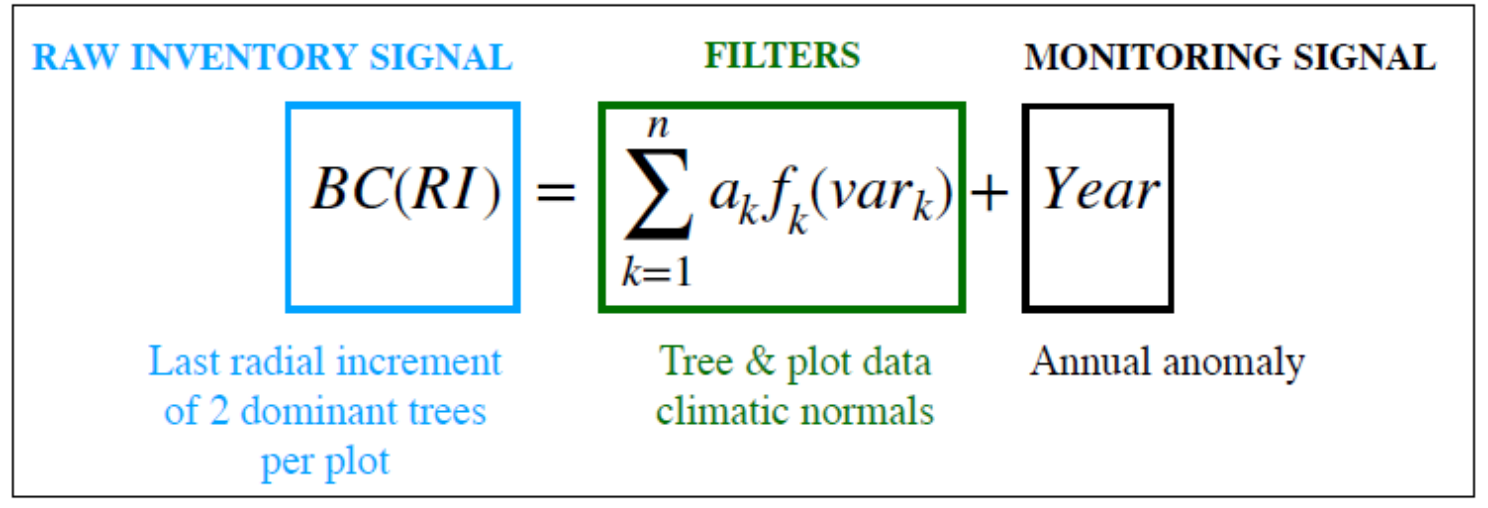

\section{RADIAL GROWTH ANOMALY CHRONOLOGY}

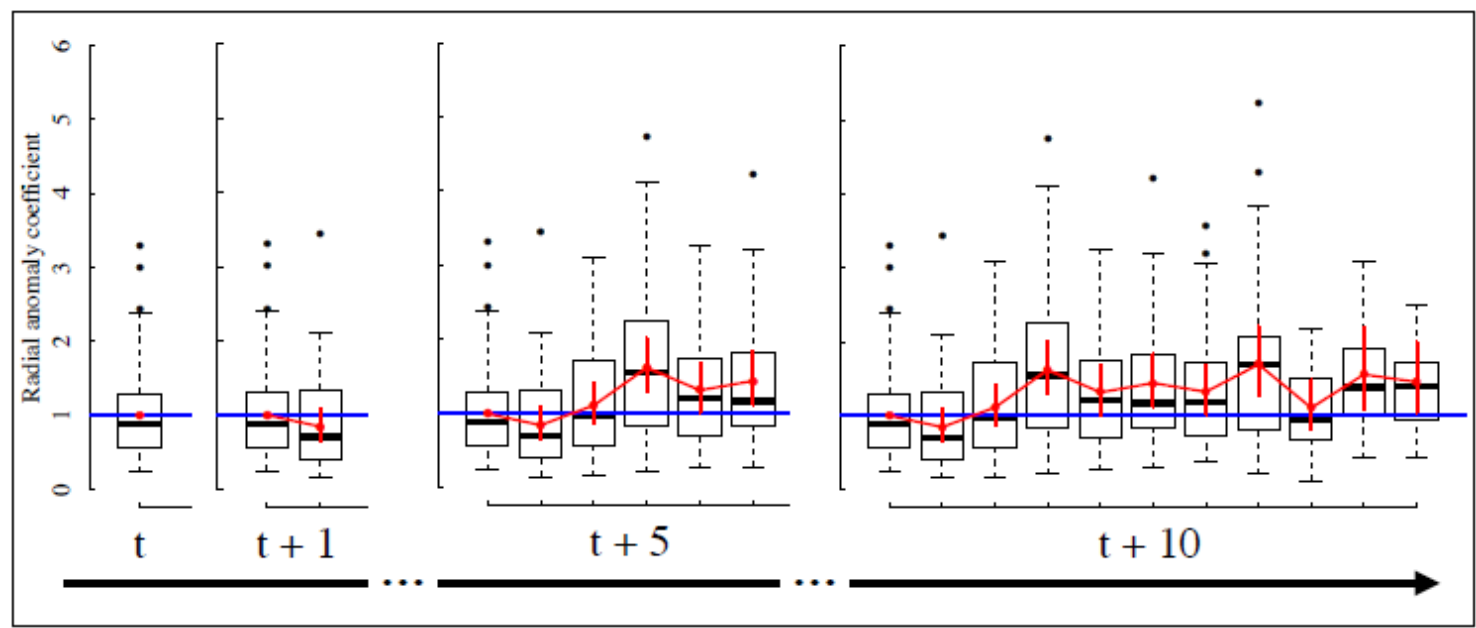

Fig. 1. Methodological flow chart of the study. 

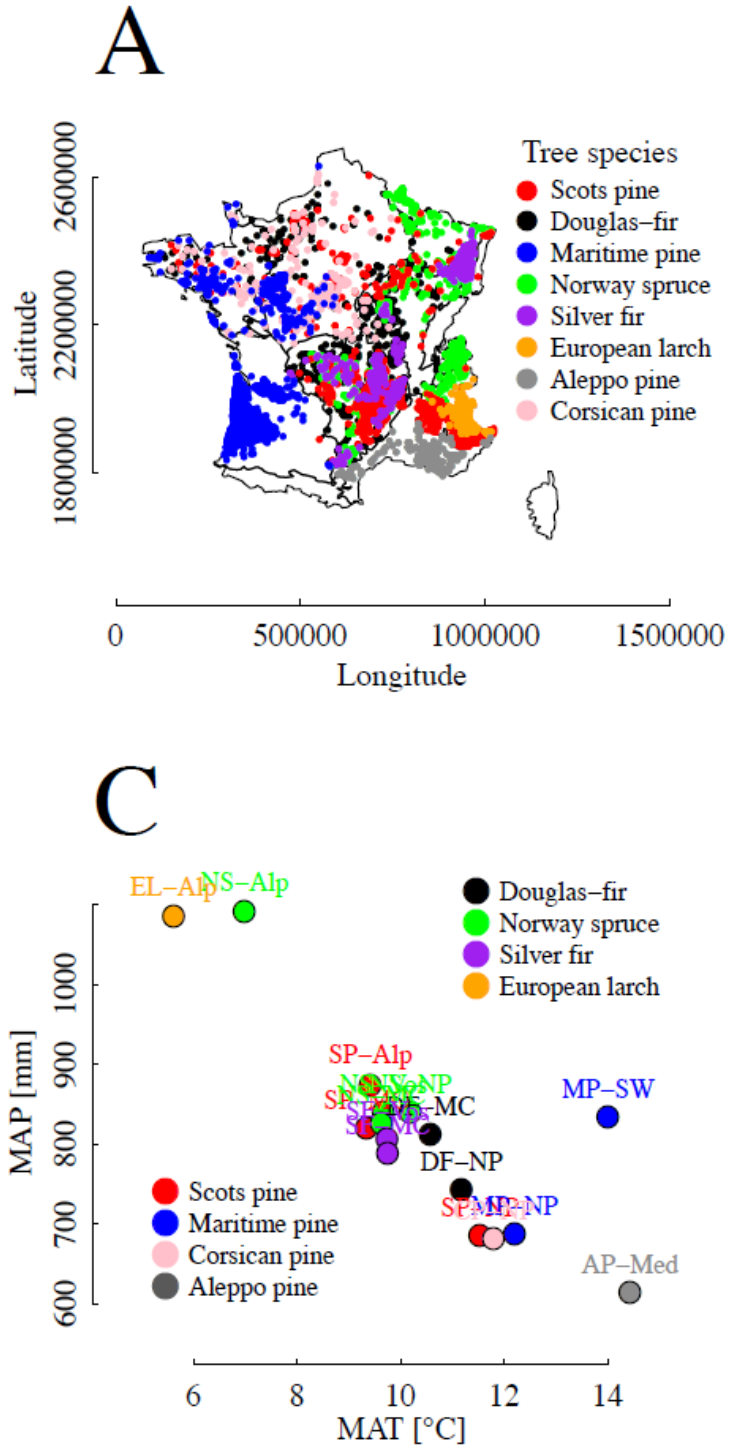
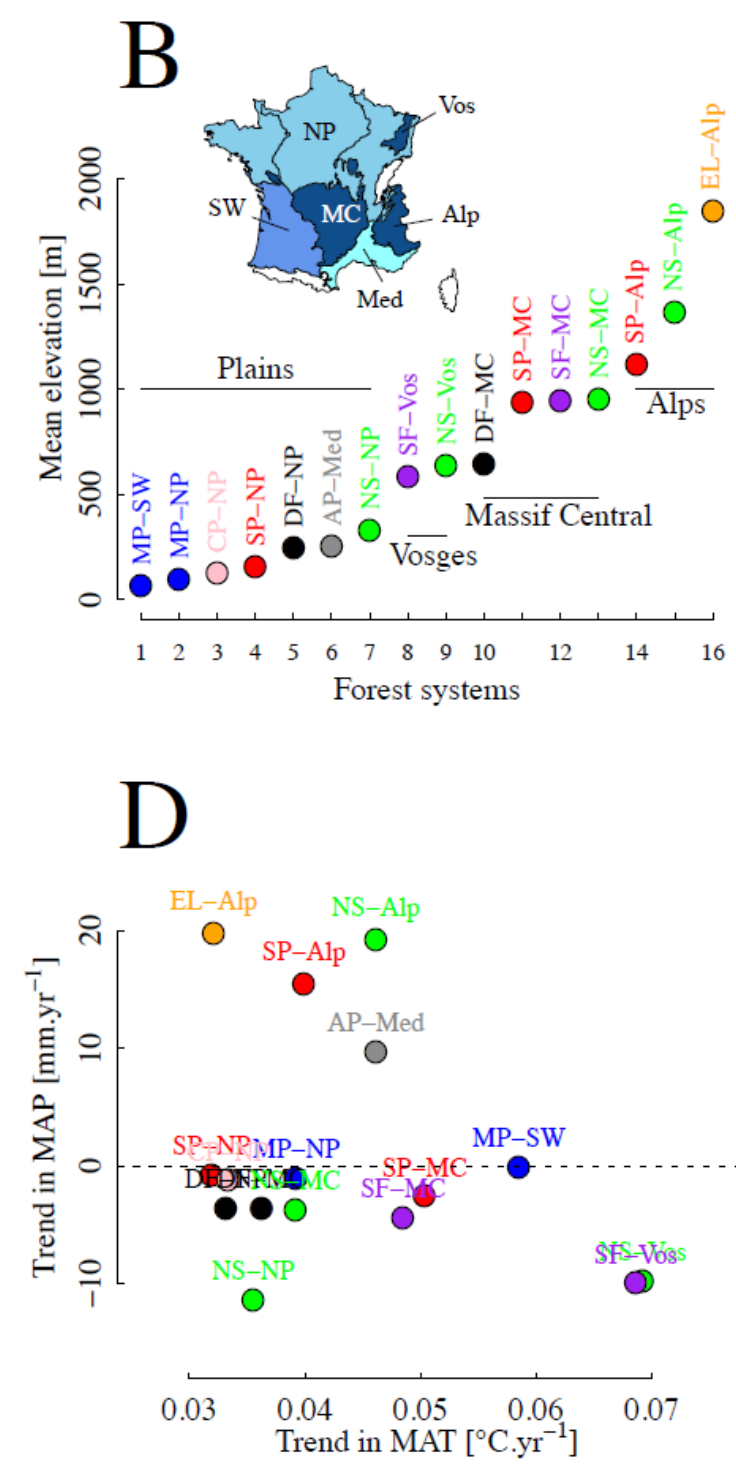

Fig. 2. Geographic and climatic positioning of the forest systems under study.

A. Location of selected plots for each of the eight focus tree species. B. Mean elevation of forest systems in meters above sea level. C. Mean annual temperature (MAT) vs. mean annual precipitation (MAP). D. Trend in MAT vs. trend in MAP. Mean annual variables and trends were computed over the 2006-2016 study period based on the climate data of plots included in each forest system (panel A). 

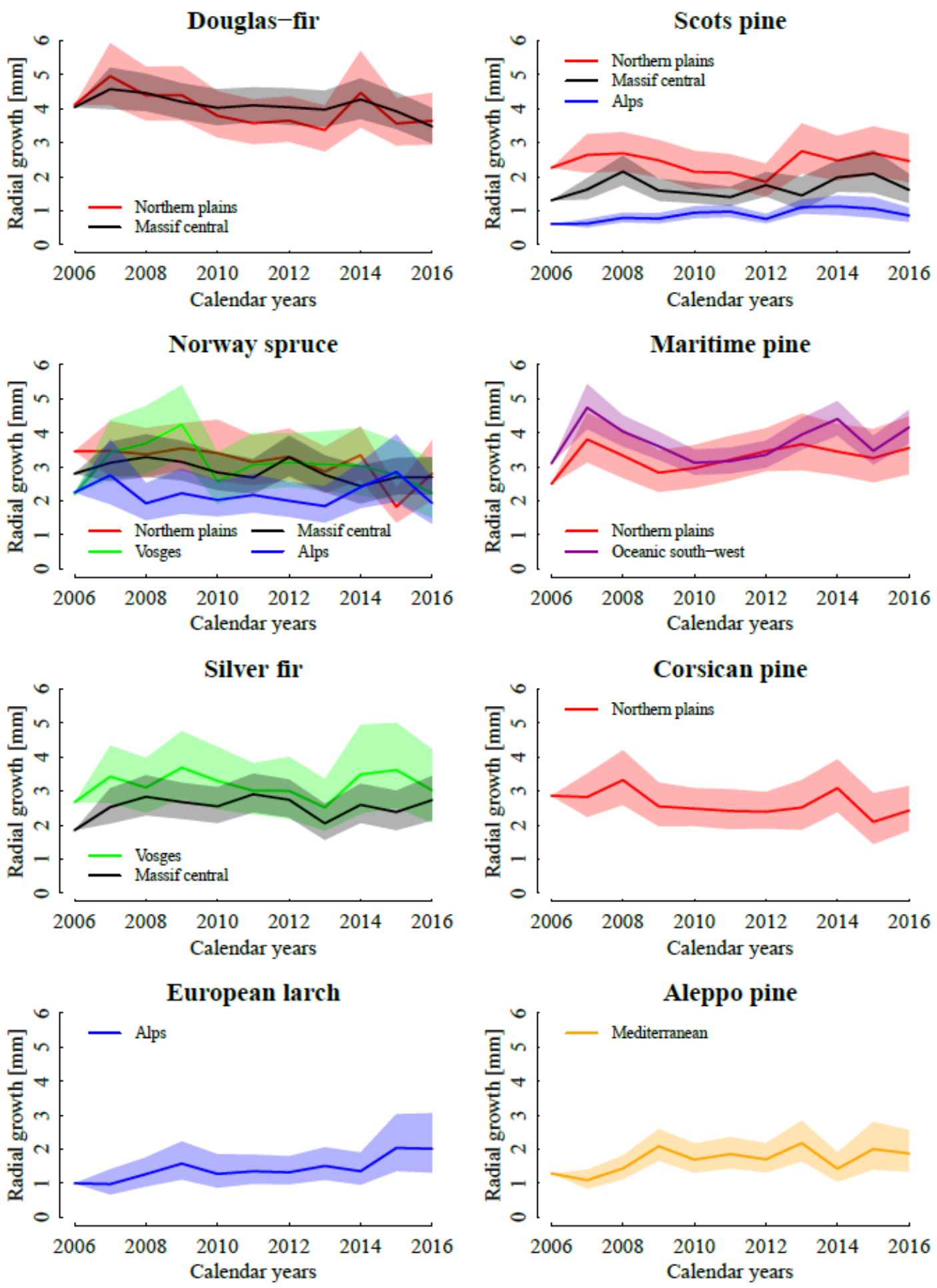

Fig. 3. Growth chronologies and their $95 \%$ bilateral confidence interval across target tree species and ecological regions over the 2006-2016 period. Annual radial growth anomalies are computed with respect to the growth reference level in 2006. Standard deviations correspond to the upper and lower margins of the $95 \%$ bilateral confidence interval of a growth anomaly coefficients. 

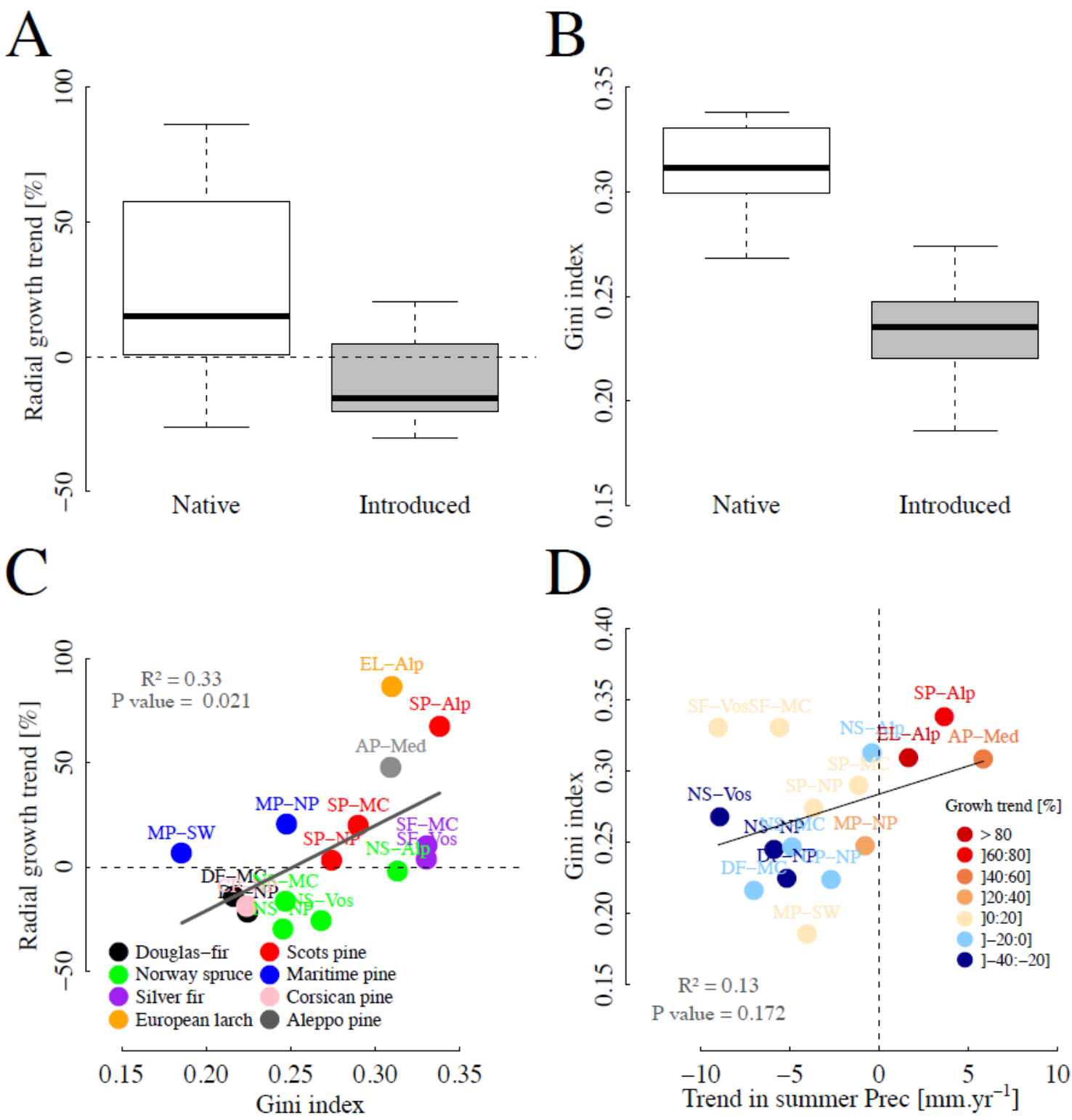

Fig. 4. Comparison of radial growth trends across native and introduced forest systems over the 2006-2016 period in relation to their stand structure and the trend in summer precipitation they face. A. Boxplot of radial growth trends in native and introduced forest systems (significant difference $(\mathrm{P}<0.05)$ identified by a Student $t$-test). B. Boxplot of the Gini index in native and introduced forest systems (significant difference $(\mathrm{P}<0.05)$ identified by a Student $t$-test). C. Association between radial growth trends and the Gini index. D. Radial growth trends in a two-dimension space defined by the trend in summer precipitation (Prec) and the Gini index. 

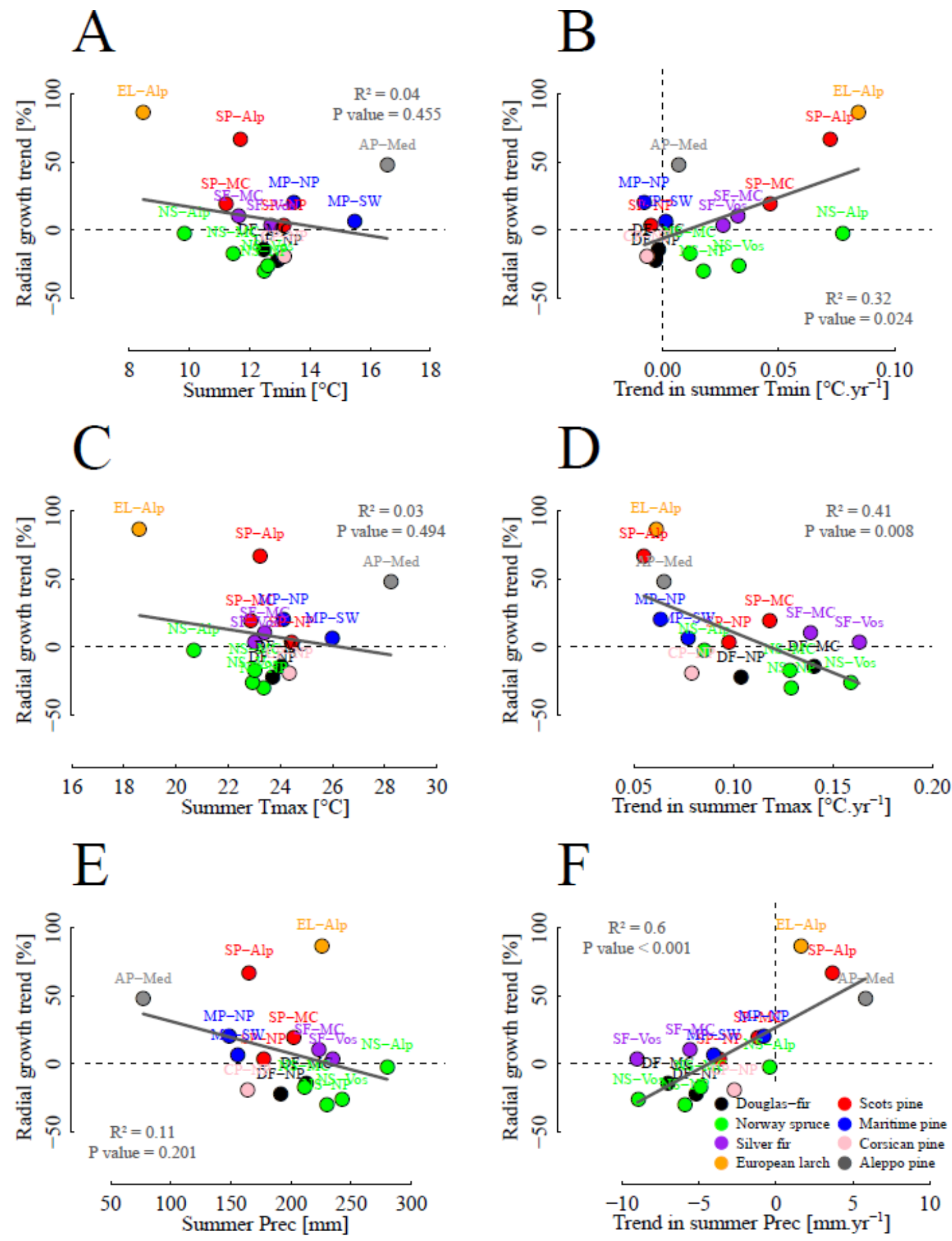

Fig. 5. Associations between radial growth trends and seasonal climate (average and trend) across forest systems over the 2006-2016 period. A. Summer minimum temperature; B. Trend in summer minimum temperature; C. Summer maximum temperature; D. Trend in summer maximum temperature; E. Summer precipitation sums; F. Trend in summer precipitation sums. The linear regression of each association is displayed by a gray line and its $\mathrm{R}^{2}$ and $P$ value indicated on each panel. For more information regarding model's names please refer to Table 2. 